\title{
Flora Polínica da Reserva do Parque Estadual das Fontes do Ipiranga (São Paulo, SP, Brasil). Família: 88 - Myrtaceae
}

\author{
[Dingela Maria da Silva Corrêa ${ }^{1,2}$, Sheila Silva Rodrigues ${ }^{1}$, Allan Carlos Pscheidt ${ }^{1}$, \\ Higor Antonio-Domingues ${ }^{1}$, Maria Amélia Vitorino da Cruz Barros ${ }^{1}$ e Carolina Brandão Coelho ${ }^{1}$
}

Recebido: 4.05.2018; aceito: 8.08.2018

\begin{abstract}
Pollen flora of the Reserva do Parque Estadual das Fontes do Ipiranga (São Paulo, São Paulo State, Brazil). Family: 88-Myrtaceae). This work presents a study of pollen grains of 55 species from 15 genera of Myrtaceae occurring in the "Reserva do Parque Estadual das Fontes do Ipiranga". The following taxa are included: Blepharocalyx salicifolius (Kunth) O. Berg, Calyptranthes concinna DC., C. grandifolia O. Berg, Campomanesia eugenioides (Cambess.) D. Legrand ex Landrum, C. guaviroba (DC.) Kiaerk., C. guazumifolia (Cambess.) O. Berg, C. phaea (O. Berg) Landrum, C. pubescens (DC) O. Berg, Eugenia beaurepaireana (Kiaersk.) D. Legrand, E. bimarginata DC., E. cerasiflora Miq., E. cereja D. Legrand, E. convexinervia D. Legrand, E. dodonaeifolia Cambess., E. excelsa O. Berg, E. handroana D. Legrand, E. neoglomerata Sobral, E. neoverrucosa Sobral, E. pruinosa D. Legrand, E. punicifolia (Kunth) DC., E. pyriformis Cambess., E. speciosa Cambess., E. stigmatosa DC., Gomidesia affinis (Cambess.) D. Legrand, G. anacardiaefolia (Gardner) O. Berg, G. sellowiana O. Berg, G. tijucensis (Kiaersk.) D. Legrand, Marlierea parviflora O. Berg, M. racemosa (Vell.) Kiaersk., Myrcengenia rufescens (DC.) D. Legrand \& Kausel, Myrcia amazonica DC., M. citrifolia (Aubl.) Urb., M. fallax (Rich.) DC., M. guianensis (Aubl.), M. laruotteana Cambess., M. laxiflora Cambess., M. macrocarpa DC., M. multiflora (Lam.) DC., M. pubipetala Miq., M. pulchra (O. Berg) Kiaersk., M. retorta Cambess., M. rostrata DC., M. tenuivenosa Kiaersk, $M$. tomentosa (Aubl.) DC., M. venulosa DC., Myrciaria delicatula (DC.) O. Berg, M. floribunda (H. West ex Willd.) O. Berg, Neomitranthes pedicellata (Burret) Mattos, Pimenta pseudocaryophyllus (Gomes) Landrum, Psidium cattleyanum Sabine, P. cinereum Mart. ex DC., P. guineense Sw., P. myrtoides O. Berg, P. rufum Mart. ex DC., and Siphoneugena widgreniana O. Berg. Descriptions, illustrations, and observations are presented for all studied taxa.
\end{abstract}

Keywords: Atlantic forest, Myrteae, pollen, pollen morphology

RESUMO - (Flora polínica da Reserva do Parque Estadual das Fontes do Ipiranga (São Paulo, SP, Brasil). Família: 88-Myrtaceae. No presente trabalho foram estudados os grãos de pólen de 55 espécies pertencentes a 15 gêneros da família Myrtaceae ocorrentes na "Reserva do Parque Estadual da Fontes do Ipiranga". Os seguintes táxons são incluídos: Blepharocalyx salicifolius (Kunth) O. Berg, Calyptranthes concinna DC., C. grandifolia O. Berg, Campomanesia eugenioides (Cambess.) D. Legrand ex Landrum, C. guaviroba (DC.) Kiaerk., C. guazumifolia (Cambess.) O. Berg, C. phaea (O. Berg) Landrum, C. pubescens (DC) O. Berg, Eugenia beaurepaireana (Kiaersk.) D. Legrand, E. bimarginata DC., E. cerasiflora Miq., E. cereja D. Legrand, E. convexinervia D. Legrand, E. dodonaeifolia Cambess., E. excelsa O. Berg, E. handroana D. Legrand, E. neoglomerata Sobral, E. neoverrucosa Sobral, E. pruinosa D. Legrand, E. punicifolia (Kunth) DC., E. pyriformis Cambess., E. speciosa Cambess., E. stigmatosa DC., Gomidesia affinis (Cambess.) D. Legrand, G. anacardiaefolia (Gardner) O. Berg, G. sellowiana O. Berg, G. tijucensis (Kiaersk.) D. Legrand, Marlierea parviflora O. Berg, M. racemosa (Vell.) Kiaersk., Myrceugenia rufescens (DC.) D. Legrand \& Kausel, Myrcia amazonica DC., M. citrifolia (Aubl.) Urb., M. fallax (Rich.) DC., M. guianensis (Aubl.), M. laruotteana Cambess., M. laxiflora Cambess., M. macrocarpa DC., M. multiflora (Lam.) DC., M. pubipetala Miq., M. pulchra (O. Berg) Kiaersk., M. retorta Cambess., M. rostrata DC., M. tenuivenosa Kiaersk, M. tomentosa (Aubl.) DC., M. venulosa D.C., Myrciaria delicatula (DC.) O. Berg, M. floribunda (H. West ex Willd.) O. Berg, Neomitranthes pedicellata (Burret) Mattos, Pimenta pseudocaryophyllus (Gomes) Landrum, Psidium cattleyanum Sabine, P. cinereum Mart. ex DC., P. guineense Sw., P. myrtoides O. Berg, P. rufum Mart ex DC. e Siphonengena widgreniana O. Berg. Para todos os táxons estudados são apresentadas descrições, ilustrações e observações.

Palavras-chave: Mata Atlântica, morfologia polínica, Myrteae, pólen

1. Instituto de Botânica, Núcleo de Pesquisa em Palinologia, Avenida Miguel Stéfano, 3687, 04301-902 São Paulo, SP, Brazil

2. Autor para correspondência: angelamsc2000@yahoo.com.br 


\section{Introdução}

O presente trabalho faz parte do projeto elaborado por Melhem et al. (1984), que visa caracterizar morfologicamente os grãos de pólen das famílias ocorrentes na Reserva do Parque Estadual das Fontes do Ipiranga (PEFI), com o objetivo de complementar os levantamentos taxonômicos realizados na mesma área segundo planejamento apresentado por Melhem et al. (1981) e finalizado em Nakajima et al. (2001). O formato atual segue Cruz-Barros \& Souza (2005).

De acordo com Kawasaki (2000), a família Myrtaceae está representada na Reserva por 15 gêneros e 55 espécies: Blepharocalyx O. Berg (B. salicifolius (Kunth) O. Berg), Calyptranthes Sw. (C. concinna DC., C. grandifolia O. Berg), Campomanesia Ruíz \& Pav. (C. eugenioides (Cambess.) D. Legrand ex Landrum, C. guaviroba (DC.) Kiaerk., C. guazumifolia (Cambess.) O. Berg, C. phaea (O. Berg) Landrum, C. pubescens (DC) O. Berg), Eugenia L. (E. beaurepaireana (Kiaersk.) D. Legrand, E. bimarginata DC., E. cerasiflora Miq. E. cereja D. Legrand, E. convexinervia D. Legrand, E. dodonaeifolia Cambess., E. excelsa O. Berg, E. handroana D. Legrand, E. neoglomerata Sobral, E. neoverrucosa Sobral, E. pruinosa D. Legrand, E. punicifolia (Kunth) DC., E. pyriformis Cambess., $E$. speciosa Cambess., E. stigmatosa DC.), Gomidesia O. Berg (G. affinis (Cambess.) D. Legrand, G. anacardiaefolia (Gardner) O. Berg, G. sellowiana O. Berg, G. tijucensis (Kiaersk.) D. Legrand), Marlierea Cambess. (M. parviflora O. Ber, M. racemosa (Vell.) Kiaersk.), Myrceugenia O. Berg (M. rufescens (DC.) D. Legrand \& Kausel), Myrcia DC. (M. amazonica DC., M. citrifolia (Aubl.) Urb., M. fallax (Rich.) DC., M. guianensis (Aubl.), M. laruotteana Cambess., $M$. laxiflora Cambess., M. macrocarpa DC., M. multiflora (Lam.) DC., M. pubipetala Miq., M. pulchra (O. Berg) Kiaersk., M. retorta Cambess., M. rostrata DC., $M$. tenuivenosa Kiaersk, M. tomentosa (Aubl.) DC., $M$. venulosa D.C.), Myrciaria O. Berg (M. delicatula (DC.) O. Berg, M. floribunda (H. West ex Willd.) O. Berg), Neomitranthes (Kausel) D. Legrand. (N. pedicellata (Burret) Mattos), Pimenta Lindl. (P. pseudocaryophyllus (Gomes) Landrum), Psidium L. (P. cattleyanum Sabine, P. cinereum Mart. ex DC., $P$. guineense Sw., P. myrtoides O. Berg, P. rufum Mart ex DC.), Siphoneugena O. Berg (S. widgreniana O. Berg).

Segundo dados disponíveis na literatura as Myrtaceae apresentam grãos de pólen em mônades, com âmbito, triangular a quadrangular, oblatos, suboblatos, oblato-esferoidais a prolatoesferoidais, 3-(4-5)-colporados, sincolporados, colpos longos, estreitos, endoabertura lalongada de difícil visualização, exina tectada, semitectada, rugulada, reticulada, microrreticulada, estriada (Erdtman 1952, Lieu \& Melhem 1973, Barth \& Barbosa (1972), Tornhill et al. (2012), Tuler et al. (2016)).

\section{Material e métodos}

Os botões florais utilizados para este trabalho foram coletados de material herborizado depositado no Herbário Científico do Estado "Maria Eneyda P. Kauffmann Fidalgo" (SP).

Os grãos de pólen foram preparados segundo o método de acetólise (Erdtman 1960) e moficado por Melhem et al. (2003). As ilustrações dos grãos de pólen acetolisados foram obtidas digitalmente em microscopia óptica (MO), utilizando-se fotomicroscópio Olympus BX 50 acoplado a microcomputador (PC), com o programa ImagePro Plus versão 3.0 para Windows. As ilustrações em microscopia eletrônica de varredura (MEV) seguiu-se a técnica proposta por Melhem et al. (2003), utilizando-se grãos de pólen acetolisados e eletromicrografados no microscópio eletrônico de varredura modelo PHILIPS XL Series XL 20, S/W ver. 5.21. A terminologia adotada está de acordo com Barth e Melhem (1988) e Punt et al. (2007).

Na maioria das espécies de Myrtaceae os grãos de pólen raramente permanecem posicionados nas lâminas em vista equatorial, impossibilitando, dessa forma, a tomada das medidas nesta vista, tais como diâmetros e aberturas, sendo esta última apenas descrita. As espécies Neomitranthes pedicellata (Burret) Mattos, Eugenia pruinosa D. Legand e Psidium myrtoides $\mathrm{O}$. Berg, não foram estudados por apresentarem apenas material com fruto e/ou por serem material tipo.

As lâminas com o material polínico encontram-se depositadas na palinoteca do Núcleo de Pesquisa em Palinologia do Instituto de Botânica.

\section{Resultados e Discussão}

\section{Blepharocalyx O. Berg}

\section{Blepharocalyx salicifolius (Kunth)}

Figuras 1-3 

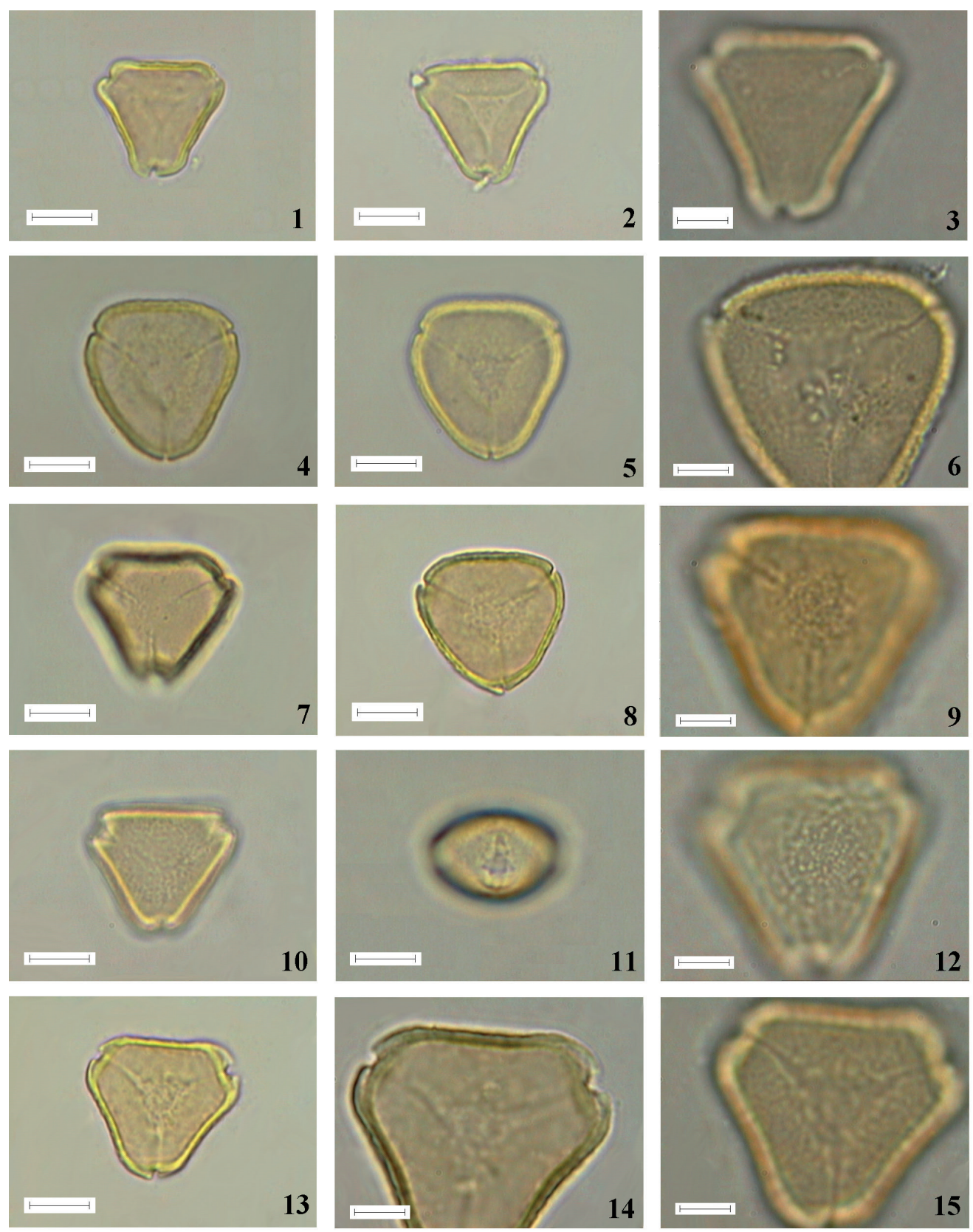

Figuras 1-15. Fotomicrografias dos grãos de pólen de Myrtaceae. 1-3. Blepharocalyx salicifolius (Kunth) O. Berg. 1. Contorno na vista polar. 2. Vista polar mostrando aberturas parassincolporadas. 3. Ornamentação da exina. 4-6. Calyptrantes concinna DC. 4. Contorno na vista polar. 5. Vista polar mostrando aberturas parassincolporadas. 6. Ornamentação da exina. 7-9. Calyptrantes grandifolia O. Berg. 7. Grão de pólen heteropolar, mostrando um lado da vista polar com aberturas não parassincolporadas. 8. Grão de pólen heteropolar, mostrando outro lado da vista polar com aberturas parassincolporadas. 9. Ornamentação da exina. 10-12. Campomanesia eugenioides (Cambess.) D. Legrand ex Landrum. 10. Vista polar mostrando aberturas sincolporadas. 11. Vista equatorial mostrando o cólporo. 12. Ornamentação da exina. 13-15. Campomanesia guaviroba (DC.) Kiaerk. 13. Vista polar mostrando aberturas parassincolporadas. 14. Corte óptico na vista polar. 15. Ornamentação da exina. Escala: nas figuras 1, 2, 4, 5, 7, 8, 10, 11, $13=10 \mu \mathrm{m}$; figures 3, 6, 9, 12, 14, 15=5 $\mu$ m.

Figures 1-15. Photomicrographs of Myrtaceae pollen grains. 1-3. Blepharocalyx salicifolius (Kunth) O. Berg. 1. Polar view, outline. 2. Polar view showing the parassincolporate apertures. 3. Ornamentation. 4-6. Calyptrantes concinna DC. 4. Polar view, outline. 5. Polar view showing the parassincolporate apertures. 6. Ornamentation. 7-9. Calyptrantes grandifolia O. Berg. 7. Heteropolar pollen grain, showing the side of non-parassincolporate apertures. 8. Heteropolar pollen grains showing the other side of parassincolporate apertures. 9. Ornamentation. 10-12. Campomanesia eugenioides (Cambess.) D. Legrand ex Landrum. 10. Polar view, showing the sincolporate apertures. 11. Equatorial view showing the colporus. 12. Ornamentation. 13-15. Campomanesia guaviroba (DC.) Kiaerk. 13. Polar view showing the parassincolporate apertures. 14. Polar view, optical section. 15. Ornamentation. Scale: figures 1, 2, 4, 5, 7, 8, 10, 11, 13 = $10 \mu \mathrm{m}$; figures $3,6,9,12,14,15=5 \mu \mathrm{m}$. 
Forma: oblata, âmbito triangular, raramente quadrangular.

Aberturas: 3-(4)-colporadas, cólporos irregularmente parassincolporados, sem fastígio, cólporos com margem delgada, endoabertura lalongada de difícil visualização.

Exina: rugulada, sexina ligeiramente mais espessa que a nexina.

Medidas $(\mu \mathrm{m}): \mathrm{P}=11,3 \pm 0,4 ; \mathrm{E}=21,1 \pm 0,2$; eixo equatorial em vista polar $=19,7 \pm 0,3$; exina ca. 2,2 , sexina ca. 1,2 e nexina ca. 1,0 .

Observações: o espécime da Reserva M. Kuhmann s.n. (SP79831) citado por Kawasaki (2000), não foi estudado por possuir apenas fruto. Tornhill et al. (2012) descreveram os grãos de pólen dessa espécie como oblato-esferoidais, 3-colporados, brevicolpados e exina verrucada, divergindo do presente estudo por apresentarem forma oblata, cólporos irregularmente parassincolporados e exina rugulada. Divergências na forma dos grãos de pólen de todas as espécies analisadas por esses autores, deve-se fato dos mesmos utilizarem grãos não acetolisados nas mensurações em MEV.

Material estudado: BRASIL. São Paulo: Campos do Jordão, 4-XII-1977, L.R. Landrun 2795 (SP).

\section{Calyptranthes Sw.}

Grãos de pólen com forma oblata, âmbito triangular, 3-colporados, cólporos irregularmente parassincolporados, sem fastígio, endoabertura lalongada de difícil visualização, exina ruguladoperfurada, sexina mais delgada que ou da mesma espessura que a nexina. Não foi possível elaborar uma chave polínica já que as espécies são morfologicamente homogêneas.

\section{Calyptranthes concinna DC.}

Figuras 4-6

Medidas $(\mu \mathrm{m}): \mathrm{P}=12,7 \pm 0,8 ; \mathrm{E}=25,0 \pm 0,1 ;$ eixo equatorial em vista polar $=24,1 \pm 0,3$; exina ca. 1,9 , sexina ca. 0,9 e nexina ca. 1,00 .

Observações: Barth \& Barbosa (1972) ao estudarem 140 espécies de Myrtaceae de diversos gêneros ocorrentes em Santa Catarina estabeleceu grupos polínicos de acordo com os tipos de aberturas e subgrupos de acordo com a ornamentação da exina. As referidas autoras analisaram duas variedades dessa espécie, Calyptranthes concinna var. concinna e $C$. concinna var. paulistana D. Legrand e enquadraram seus grãos de pólen no grupo polínico 1 com cólporos simplesmente 3-colporados com exina insulada. Já no presente estudo estes apresentaram cólporos irregularmente parassincolporados e exina ruguladoperfurada. Tornhill et al. (2012) os descreveram como oblato-esferoidais, 3-colporados, brevicolpados, com exina granulada ou escabrada diferentemente do presente trabalho.

Material estudado: 8-I-1932, O. Handro s.n. (SP28667).

\section{Calyptranthes grandifolia $\mathrm{O}$. Berg}

Figuras 7-9

Medidas $(\mu \mathrm{m}): \mathrm{P}=13,6 \pm 0,2 ; \mathrm{E}=24,4 \pm 0,5$; eixo equatorial em vista polar $=22,7 \pm 0,2$; exina ca. 1,9 , sexina ca. 0,9 e nexina ca. 0,9 .

Observações: os espécimes da Reserva A.C. Filho 2 (SP) e S.L. Jung et al. 259 (SP), citados por Kawasaki (2000) não foram estudados por possuírem apenas fruto. Barth \& Barbosa (1972) estudaram dois espécimes de Calyptranthes grandifolia var. rufa (O. Berg) D. Legrand e enquadraram em grupos diferentes. O espécime Reitz e Klein 6335 no grupo 1. simplesmente 3-colporados, com exina insulada e o espécime Reitz e Klein 8246, no grupo 3. heteropolares, 3- longicolporados e 3-sincolporados às vezes 3-parassincolporados. No presente estudo foram observados apenas grãos de pólen 3-colporados, irregularmente parassincolporados e exina ruguladoperfurada, não corroborando os resultados encontrados pelas autoras. De acordo com a Flora do Brasil (2020, em construção) Calyptranthes brasiliensis Spreng. é o nome aceito para essa espécie atualmente.

Material estudado: 30-I-1934, O. Handro s.n. (SP29843).

\section{Campomanesia Ruíz \& Pav.}

Grãos de pólen com forma oblata, âmbito triangular, 3-colporados, cólporos curtos, longos a muito longos ou sincolporados a irregularmente parassincolporados, sem fastígio, endoabertura circular a lalongada ou de difícil visualização, exina rugulado-perfurada, rugulado-microrreticulada a areolada, sexina mais delgada a mais espessa que a nexina.

\section{Campomanesia eugenioides (Cambess) D. Legrand} ex Landrum

Figuras 10-12 
Aberturas: cólporos curtos ou sincolporados, endoabertura lalongada.

Exina: rugulado-microrreticulada, sexina mais espessa que a nexina.

Medidas $(\mu \mathrm{m}): \mathrm{P}=16,2 \pm 0,2 ; \mathrm{E}=22,9 \pm 0,2 ;$ eixo equatorial em vista polar $=21,5 \pm 0,2$; cólporo compr. ca. 11,6, larg. ca. 2,2; endoabertura compr. ca. 3,2, larg. ca. 6,0 ; exina ca. 1,7 , sexina ca 1,0 e nexina ca. 0,8 .

Observações: Barth \& Barbosa (1972) ao estudarem essa espécie enquadraram seus grãos de pólen no grupo 1. simplesmente 3-colporado e com exina granulada. $\mathrm{O}$ presente trabalho apresentou grãos de pólen isopolares, 3-colporados e grãos 3-sincolporados ocorrentes num mesmo espécime. Já a ornamentação da exina foi aqui definida como rugulado-microrreticulada.

Material estudado: 10-XI-1931, O. Handro s.n. (SP26668).

\section{Campomanesia guaviroba (DC.) Kiaersk.}

Figuras 13-15

Aberturas: cólporos irregularmente parassincolporados, endoabertura de difícil visualização.

Exina: areolada, sexina da mesma espessura que a nexina.

Medidas $(\mu \mathrm{m}): \mathrm{P}=12,2 ; \mathrm{E}=24,4$; eixo equatorial em vista polar $=23,1$; exina ca. 1,7 , sexina ca. 0,9 , nexina ca. 0,9 .

Observações: o material da Reserva M. Kuhlmann 3348 (SP), citado por Kawasaki (2000) não foi estudado por possuir apenas fruto. Ao estudarem essa espécie, Barth \& Barbosa (1972) enquadraram seus grãos de pólen no grupo 1. simplesmente 3-colporado e com exina granulada. Os resultados do presente estudo divergiram das referidas autoras quanto ao tipo apertural e quanto a ornamentação da exina, sendo aqui considerados irregularmente parassincolporados e com exina areolada.

Material estudado: BRASIL. São PAUlo: Ipeúna, Rodrigues, R.R. \& Zandoval, J.A. s.n. 12-XII-1989 (SP296889).

\section{Campomanesia guazumifolia (Cambess.) O. Berg} Figuras 16-18

Abertura: cólporos longos, endoabertura lalongada.

Exina: rugulado-microrreticulada, sexina mais delgada que a nexina.
Medidas $(\mu \mathrm{m}): \mathrm{P}=21,6 \pm 0,2 ; \mathrm{E}=29,8 \pm 0,2 ;$ eixo equatorial em vista polar $=28,2 \pm 0,2$; cólporos compr. ca. 15,2, larg. ca. 2,1; endoabertura compr. ca. 7,3, larg. ca. 8,8; exina ca.2,0, sexina ca. 0,9 e nexina ca. 1,2 .

Observações: Tornhill et al. (2012) ao analisarem a espécie, descreveram seus grãos de pólen como oblato-esferoidais, 3-colporados, brevicolpados, com exina granulada ou escabrada. Confrontando os resultados dos referidos autores com os aqui obtidos verificou-se que houve divergência quanto à forma dos grãos de pólen, tamanho dos cólporos e ornamentação da exina. Esses autores utilizaram grãos de pólen não acetolisados o que justifica a diferença na forma dos grãos, já quanto à ornamentação, aqui foram descritos como tendo exina rugulado-microrreticulada.

Material estudado: 28-X-1931, F.C. Hoehne s.n. (SP28408).

\section{Campomanesia phaea (O. Berg) Landrum}

Figuras 19-20

Aberturas: cólporos muito longos, endoabertura circular.

Exina: rugulado-perfurada, sexina mais delgada que a nexina.

Medidas $(\mu \mathrm{m}):$ M. Kirizawa 250: $\mathrm{P}=21,6 \pm 0,2$; $\mathrm{E}=29,8 \pm 0,2$; eixo equatorial em vista polar $=28,2 \pm 0,2$; cólporo compr. ca. 9,5, larg. ca. 1,2; endoabertura compr. ca. 9,2, larg. ca. 9,4; exina ca. 1,8 , sexina ca. 0,8 , e nexina ca. 1,0 .

O. Handro s.n. (SP48590): $\mathrm{P}=14,6 ; \mathrm{E}=22,9$; eixo equatorial em vista polar $=21,1$.

Observações: o espécime da Reserva M. Kirizawa 333 (SP) citado por citado por Kawasaki (2000), não foi estudado por possuir apenas fruto.

Material estudado: 26-X-1978, M. Kirizawa 250 (SP), 18-IX-1945, O. Handro s.n. (SP48590).

\section{Campomanesia pubescens (DC.) O. Berg} Figuras 21-23

Aberturas: cólporos longos, endoabertura lalongada.

Exina: rugulado-perfurada, sexina mais delgada que a nexina.

Medidas ( $\mu \mathrm{m})$ : O. Handro s.n. (SP46013): $\mathrm{P}=19,4 \pm 0,2 ; \mathrm{E}=28,2 \pm 0,3$; eixo equatorial em 

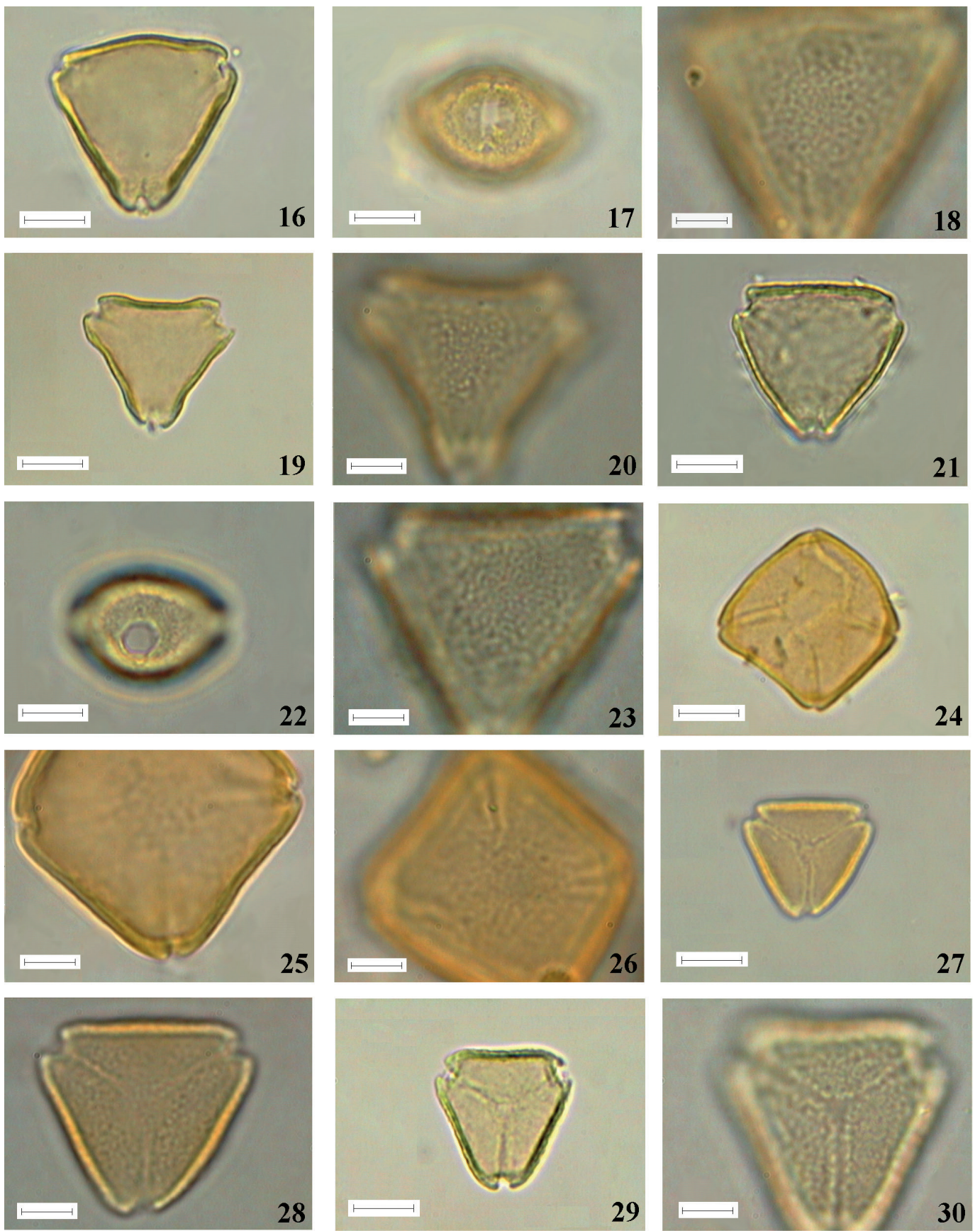

Figuras 16-30. Fotomicrografias dos grãos de pólen de Myrtaceae. 16-18. Campomanesia guazumifolia (Cambess.) O. Berg. 16. Contorno na vista polar. 17. Vista equatorial mostrando o cólporo. 18. Ornamentação da exina. 19-20. Campomanesia phaea (O. Berg) Landrum. 19. Contorno na vista polar. 20. Ornamentação da exina. 21-23. Campomanesia pubescens (DC) O. Berg). 21. Contorno na vista polar. 22. Vista equatorial mostrando o cólporo. 23. Ornamentação da exina. 24-26. Eugenia bimarginata DC. 24. Contorno na vista polar, mostrando as quatro aberturas. 25. Corte óptico na vista polar. 26. Ornamentação da exina. 27-28. Eugenia cerasifolia Miq. 27. Vista polar mostrando aberturas parassincolporadas. 28. Ornamentação da exina. 29-30. Eugenia excelsa O. Berg. 29. Vista polar mostrando aberturas sincolporadas. 30. Ornamentação da exina. Escalas nas figuras 16, 17, 19, 21, 22, 24, 27, $29=10 \mu \mathrm{m}$., demais figuras = $5 \mu \mathrm{m}$.

Figures 16-30. Photomicrographs of Myrtaceae pollen grains. 16-18. Campomanesia guazumifolia (Cambess.) O. Berg. 16. Polar view, outline. 17. Equatorial view showing the colporus. 18. Ornamentation. 19-20. Campomanesia phaea (O. Berg) Landrum. 19. Polar view, outline. 20. Ornamentation. 21-23. Campomanesia pubescens (DC) O. Berg). 21. Polar view, outline. 22. Equatorial view showing the colporus. 23. Ornamentation. 24-26. Eugenia bimarginata. DC. 24. Polar view in outline, showing the four apertures. 25. Polar view, optical section. 26. Ornamentation. 27-28. Eugenia cerasifolia Miq. 27. Polar view showing the parassincolporate apertures. 28. Ornamentation. 29-30. Eugenia excelsa O. Berg. 29. Polar view showing the sincolporate apertures. 30. Ornamentation. Scale: figures 16, 17, 19, 21, 22, $24,27,29=10 \mu \mathrm{m}$; figures $16,18,20,23,25,26,28,30=5 \mu \mathrm{m}$. 
vista polar $=25,2 \pm 0,4$; cólporo compr. ca. 14,2, larg. ca. 2,0; endoabertura compr. ca. 6,4, larg. ca. 7,1; exina ca. 2,0 , sexina ca. 0,8 , e nexina ca. 1,1 .

F.C. Hoehne s.n. (SP 25517): $\mathrm{P}=16,4 ; \mathrm{E}=39,3$; eixo equatorial em vista polar $=21,2$.
Observações: o material da Reserva F.C. Hoehne s.n. (SP38312), citado por Kawasaki (2000) não foi estudado por escassez de material polínico.

Material estudado: 1-X-1934, O. Handro s.n. (SP46013); 12-IX-1932, F.C. Hoehne s.n. (SP25517).

\section{Chave para as espécies de Campomanesia}

1. Grãos de pólen com exina areolada

C. guavirova

1. Grãos de pólen com exina rugulado-perfurada ou rugulado-microrreticulada

2. Exina rugulado-perfurada, cólporos longos ou muito longos

3. 3-cólporos longos

C. pubescens

3. 3-cólporos muito longos

C. phaea

2. Exina rugulado-microrreticulada, cólporos longos ou curtos a sincolporados

4. 3-cólporos longos

C. guazumifolia

4. 3-cólporos curtos a sincolporados

C. engenioides

\section{Eugenia L.}

Grãos de pólen com forma oblata a suboblata, âmbito triangular, 3-4-(5)-colporados, cólporos longos, muito longos a irregularmente parassincolporados, sem fastígio, endoabertura lalongada ou de difícil visualização, exina rugulado, rugulado-perfurada a rugulado-microrreticulada, sexina mais delgada ou mais espessa que a nexina.

\section{Eugenia beaurepairiana (Kiaersk.) D. Legrand}

Forma: oblata.

Aberturas: 3-colporadas, cólporos muito longos ou raramente sincolporados ou parassincolporados, endoabertura de difícil visualização.

Exina: rugulada, sexina mais delgada que a nexina.

Medidas $(\mu \mathrm{m}): \mathrm{P}=11,7 ; \mathrm{E}=20,9$; eixo equatorial em vista polar $=18,2 \pm 0,2$; cólporos compr. 9,3, larg. 1,6; exina ca. 1,7 , sexina ca. 0,6 , e nexina ca. 1,1 .

Observações: este espécime apresentou 6\% de grãos de pólen sincolporados e $1 \%$ de parassincolporados. Barth \& Barbosa (1972) enquadraram os grãos de pólen dessa espécie no grupo 1. com aberturas simplesmente 3-colporadas e com exina granulada. As referidas autoras não observaram a presença de grãos de pólen sincolporados ou parassincolporados bem como a presença de rúgulas no espécime analisado pelas mesmas.

Material estudado: 3-X-1934, O. Handro s.n. (SP25752).

\section{Eugenia bimarginata DC.}

Figuras 24-26
Forma: oblata.

Aberturas: 4-(5)-colporadas, cólporos longos, cólporos endoabertura de difícil visualização.

Exina: rugulado-microrreticulada, sexina mais espessa que a nexina.

Medidas $(\mu \mathrm{m}):=\mathrm{P}=13,4 \pm 0,5 ; \mathrm{E}=25,8 \pm 0,3 ;$ eixo equatorial em vista polar $=25,1 \pm 0,3$; exina ca. 1,8 , sexina ca. 1,2 , e nexina ca. 0,7 .

Observações: esta espécie apresentou $84 \%$ de grãos de pólen 4-colporados e 16\% 5-colporados. Não foi possível medir os cólporos e a endoabertura devido a difícil visualização dessas estruturas.

Material estudado: 28-V-1930, F.C. Hoehne s.n. (SP26502).

\section{Eugenia cerasiflora Miq.}

Figuras 27-28

Forma: oblata.

Aberturas: 3-(4)-colporadas, cólporos parassincolporados, endoabertura de difícil visualização.

Exina: rugulado-microrreticulada, sexina mais espessa que a nexina.

Medidas ( $\mu \mathrm{m}):$ F. Barros 2307: $\mathrm{P}=11,9 \pm 0,2$; $\mathrm{E}=20,4 \pm 0,2$; eixo equatorial em vista polar $=19,6$ $\pm 0,3$; cólporo larg. ca. 1,2 ; exina ca. 2,0 , sexina ca. 1,2 e nexina ca. 0,9 .

O. Handro s.n. (SP29743): eixo equatorial em vista polar $=21,04$.

Observações: o espécime da Reserva M. Kuhlmann 3350, citado por Kawasaki (2000), não foi estudado por 
possuir apenas frutos. A espécie foi analisada por Barth \& Barbosa (1972) que enquadraram os grãos de pólen no grupo 3. grãos heteropolares, 3-longicolporadas e 3-sincolporadas as vezes 3-parassincolporadas, divergindo do presente trabalho já que estes são isopolares sincolporados a parassincolporadas. As autoras observaram também raramente grãos (4)-colporados. Quanto a ornamentação da exina Barth \& Barbosa (1972) os descreveram como sendo granulado-insulada discordando do espécime aqui analisado que apresentou exina ruguladomicrorreticulada.

Material estudado: 11-VI-1991, F. Barros 2307 (SP); 3-VI-1932, O. Handro s.n. (SP29743).

\section{Eugenia cereja D. Legrand}

Forma: oblata.

Aberturas: 3-colporadas, cólporos irregularmente parassincolporados, endoabertura lalongada.

Exina: rugulado-microrreticulada, sexina mais delgada que a nexina.

Medidas $(\mu \mathrm{m}):=\mathrm{P}=11,8 ; \mathrm{E}=20,1 ;$ eixo equatorial em vista polar $=19,0 \pm 0,2$; cólporo larg. ca. 1,7 ; endoabertura compr. ca. 2,0, larg. ca. 6,5; exina ca. 1,7 , sexina ca. 0,7 e nexina ca. 1,1 .

Observações: não foi possível estudar o espécime da Reserva O. Handro s.n. (SP35132) citado por Kawasaki (2000) por não conter material polínico. Barth \& Barbosa (1972) enquadraram os grãos de pólen dessa espécie no grupo 3. grãos heteropolares com aberturas 3-longicolporadas, 3-sincolporadas as vezes 3-parassincolporadas e com exina granuladoinsulada. O espécime aqui descrito apresentou cólporos irregularmente parassincolporados, com exina rugulado-microrreticulada, não corroborando com os resultados apresentados pelas autoras.

Material estudado: Brasil. PARAnÁ: Morretes, 6-XI-1968, G. Hastchbach 20217 (SP).

\section{Eugenia convexinervia D. Legrand}

Forma: oblata.

Aberturas: 3-colporadas, cólporos longos, endoabertura de difícil visualização.

Exina: rugulada, sexina mais delgada que a nexina.

Medidas $(\mu \mathrm{m}): \mathrm{P}=13,3 ; \mathrm{E}=21,1 ;$ eixo equatorial em vista polar $=28,7 \pm 0,1$; exina ca. 1,6 , sexina ca. 0,6 e nexina ca.0,9.
Observações: ao estudarem a espécie, Barth \& Barbosa (1972) enquadraram seus grãos de pólen no grupo 1. grãos 3-colporados e com exina granulada. Os resultados aqui obtidos corroboram os das referidas autoras quanto ao tipo de abertura, porém diverge quanto a ornamentação da exina, sendo aqui descritos como rugulados. De acordo com a Flora do Brasil (2020, em construção) Eugenia supraaxillaris Spring é o nome aceito para essa espécie atualmente.

Material estudado: 12-X-1934, O. Handro s.n. (SP 32550).

\section{Eugenia dodonaeifolia Cambess.}

Forma: oblata.

Aberturas: 3-colporadas, cólporos irregularmente parassincolporados, endoabertura de difícil visualização.

Exina: rugulada, sexina mais delgada que a nexina.

Medidas $(\mu \mathrm{m}): \mathrm{P}=11,4 ; \mathrm{E}=17,9 ;$ eixo equatorial em vista polar $=17,1 \pm 0,2$; cólporo larg. ca. 2,0 ; exina ca. 1,5 , sexina ca. 0,6 e nexina ca. 1,0 .

Material estudado: 30-X-1931, F.C. Hoehne s.n. (SP28417).

\section{Eugenia excelsa O. Berg}

Figuras 29-30

Forma: oblata.

Aberturas: 3-(4)-colporadas, cólporos parassincolporados, endoabertura de difícil visualização.

Exina: rugulado-perfurada, sexina da mesma espessura que a nexina

Medidas ( $\mu \mathrm{m})$ : M. Kuhlmann 2731 (SP): $\mathrm{P}=12,0 \pm 0,2$; $\mathrm{E}=23,2 \pm 0,3$; eixo equatorial em vista polar $=$ $21,9 \pm 0,2$; exina ca. 1,4 , sexina ca. 0,9 e nexina ca. 0,9 . R.A. Pinho 32: eixo equatorial em vista polar $=21,3$ M. Kirizawa 290: eixo equatorial em vista polar $=22,7$ F.C. Hoehne s.n. (SP32552): eixo equatorial em vista polar $=19,5$

Observações: o material da Reserva S.A.C. Chiea 159 (SP), citado por Kawasaki (2000), não foi estudado por possuir apenas fruto. Barth \& Barbosa (1972) estudaram essa espécie sob o sinônimo Eugenia obovata $\mathrm{O}$.Berg e enquadraram seus grãos de pólen no grupo 2. grãos com abertura 3-sincolporadas e exina granulada. Os resultados das autoras divergiram do presente estudo com relação a ornamentação da 
exina que aqui apresentaram ornamentação ruguladoperfurada.

Material estudado: 17-IX-1932, O. Handro s.n. (SP28737); 2-X-1933, F.C. Hoehne s.n. (SP32552); 29-IX-1977, M. Kirizawa 290 (SP); 25-X-1963, R.A. Pinho 32 (SP).

\section{Eugenia handroana D. Legrand}

Forma: suboblata.

Aberturas: 3-colporadas, cólporos irregularmente parassincolporados, endoabertura de difícil delimitação.

Exina: rugulado-perfurada, sexina mais delgada que a nexina.

Medidas $(\mu \mathrm{m}): \mathrm{P}=14,3 \pm 0,1 ; \mathrm{E}=18,1 \pm 0,2$; eixo equatorial em vista polar $=17,3 \pm 0,2$; exina ca. 1,5 , sexina ca. 0,7 e nexina ca. 0,8 .

Observações: o espécime da Reserva O. Handro s.n. (SP31083, isótipo) citado por Kawasaki (2000), não foi estudado por ser material tipo. Barth \& Barbosa (1972) enquadraram os grãos de pólen da espécie no grupo 3. grãos heteropolares com aberturas 3-longicolporadas e 3-sincolporadas as vezes 3-parassincolporadas com exina granulado-insulada. Já no presente trabalho, estesm são apenas irregularmente parassincolporadas com exina rugulado-perfurada.

Material estudado: O. Handro s.n. (SP28113).

\section{Eugenia neoglomerata Sobral}

Figura 31

Forma: oblata.

Aberturas: 3-colporadas, cólporos irregularmente parassincolporados, endoabertura lolongada.

Exina: rugulada, sexina mais delgada que a nexina.

Medidas $(\mu \mathrm{m})$ : O. Handro s.n. $(\mathrm{SP} 30221)=\mathrm{P}=10,6$; $\mathrm{E}=18,2$; eixo equatorial em vista polar $=18,5 \pm 0,2$; cólporo larg. ca. 1,0; endoabertura compr. ca. 4,5, larg. ca. 0,7; exina ca. 1,6, sexina ca. 0,7 e nexina ca. 1,0 . S. Romaniuc Neto et al. 45 (SP): eixo equatorial em vista polar $=18,4$.

Material estudado: 30-I-1933, O. Handro s.n. (SP30221); 27-IV-1982, S. Romaniuc Neto et al. 45 (SP)

\section{Eugenia neoverrucosa Sobral}

Forma: oblata.
Aberturas: 3-colporadas, cólporos irregularmente parassincolporados, endoabertura de difícil visualização.

Exina: rugulado-perfurada, sexina mais delgada que a nexina.

Medidas ( $\mu \mathrm{m}): \mathrm{P}=12,2 ; \mathrm{E}=19,3$; eixo equatorial em vista polar $=18,2 \pm 0,2$; exina ca. 1,6 , sexina ca. 0,7 e nexina ca. 0,9 .

Observações: Barth \& Barbosa (1972) estudaram essa espécie sob o sinônimo Eugenia verrucosa D.Legrand e enquadraram seus grãos de pólen no grupo 3 . heteropolares com aberturas 3-longicolporadas e 3-sincolporadas as vezes 3-parassincolporadas com exina granulado-insulada. No presente trabalho foram observadas apenas aberturas irregularmente 3-parassincolporadas e exina rugulado-perfurada.

Material estudado: 20-IV-1982, A.C. Maruffa et al. 6 (SP).

\section{Eugenia punicifolia (Kunth) DC.}

Figuras 32-33

Forma: oblata.

Aberturas: (3)-4-(5)-colporadas, cólporos sincolporados a irregularmente parassincolporados, endoabertura de difícil visualização.

Exina: rugulado-perfurada, sexina mais delgada que nexina.

Medidas $(\mu \mathrm{m})$ : Grãos de pólen 4-colporados: eixo $\mathrm{I}=29,2 \pm 0,3$; eixo $\mathrm{II}=29,5 \pm 0,3$; exina ca. 1,7 , sexina ca. 0,8 e nexina ca. 0,9 .

Grãos de pólen 3-colporados: $\mathrm{P}=18,4 ; \mathrm{E}=28,0$; eixo equatorial em vista polar $=26,9$.

Observações: os materiais da Reserva, O. Handro s.n. (SP32549, SP53428) citados por Kawasaki (2000) não foram estudados por estarem em fruto. No material aqui estudado ocorreram $63 \%$ de grãos 4-colporados, $35 \%$ de grãos 3-colporados e $2 \%$ de grãos 5-colporados.

Material estudado: Brasil. MinAs GERAIS: Grão Mogol, 13-XII-1989, J.R. Pirani et al. 12664 (SP).

\section{Eugenia pyriformis Cambess.}

Forma: oblata.

Aberturas: 3-(4)-colporadas, cólporos parassincolporados, endoabertura de difícil visualização. 

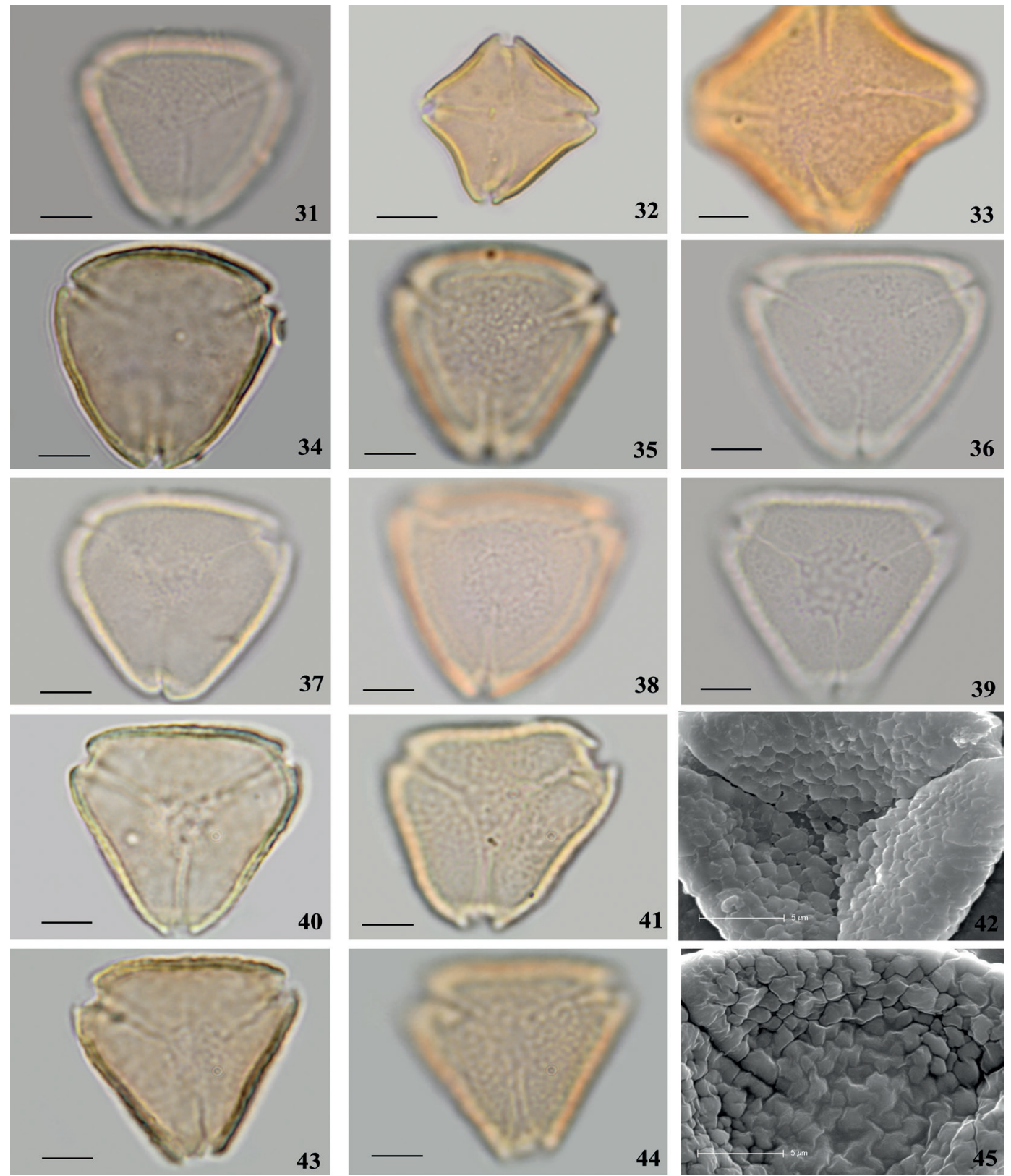

Figuras 31-45. Fotomicrografias e eletromicrografias (MEV) dos grãos de pólen de Myrtaceae. 31. Eugenia neoglomerata Sobral. Vista polar evidenciando a ornamentação. 32-33. Eugenia punicifolia (Kunth) DC. 32. Vista polar, contorno. 33. Vista polar evidenciando a ornamentação. 34-35. Gomidesia sellowiana O. Berg. 34. Vista polar, contorno. 35. Vista polar evidenciando a ornamentação. 36. Gomidesia tijucensis (Kiaersk.) D. Legrand. Vista polar evidenciando a ornamentação. 37. Marlierea parviflora O. Berg. Vista polar evidenciando a ornamentação. 38. Marlierea racemosa (Vell.) Kiaersk. Vista polar evidenciando a ornamentação. 39. Myrceugenia rufescens (DC.) D. Legrand \& Kausel. Vista polar evidenciando a ornamentação. 40-42. Myrcia amazonica DC. 40. Vista polar, contorno. 41. Vista polar evidenciando a ornamentação. 42. Detalhe da ornamentação em vista polar. 43-45. Myrcia citrifolia (Aubl.) Urb. 43. Vista polar contorno. 44. Vista polar evidenciando a ornamentação. 45. Detalhe da ornamentação em vista polar. Escala: figura $32=10 \mu \mathrm{m}$; figuras $31,33-45=5 \mu \mathrm{m}$.

Figures 31-45. Photomicrographs and scanning electron micrographs (SEM) of Myrtaceae pollen grains. 31. Eugenia neoglomerata Sobral. Polar view showing the ornamentation. e 32-33. Eugenia punicifolia (Kunth) DC. 32. Polar view, outline. 33. Polar view showing the ornamentation. 34-35. Gomidesia sellowiana O. Berg. 34. Polar view, outline. 35. Polar view showing the ornamentation. 36. Gomidesia tijucensis (Kiaersk.) D. Legrand. Polar view showing the ornamentation. 37. Marlierea parviflora O. Berg. Polar view showing the ornamentation. 38. Marlierea racemosa (Vell.) Kiaersk. Polar view showing the ornamentation. 39. Myrceugenia rufescens (DC.) D. Legrand \& Kausel. Polar view showing the ornamentation. 40-42. Myrcia amazonica DC. 40. Polar view, outline. 41. Polar view showing the ornamentation. 42. Detail of the ornamentation. 43-45. Myrcia citrifolia (Aubl.) Urban. 43. Polar view, outline. 44. Polar view showing the ornamentation. 45. Detail of the ornamentation. Scale: figure $32=10 \mu \mathrm{m}$; figures 31 and 33-45=5 $\mu \mathrm{m}$. 
Exina: rugulado-perfurada, sexina mais delgada que a nexina.

Medidas $(\mu \mathrm{m}): \mathrm{P}=12,1 ; \mathrm{E}=22,1$; eixo equatorial $\mathrm{em}$ vista polar $=20,2 \pm 0,2$; exina ca. 1,6 , sexina ca. 0,7 e nexina ca. 0,9 .

Observações: os espécimes da Reserva F.C. Hoehne s.n. (SP4147), M. Kirizawa 295 (SP), citados por Kawasaki (2000) não foram estudados por possuírem apenas frutos. Ao estudarem a espécie, Barth \& Barbosa (1972) enquadraram seus grãos de pólen do Grupo 1. com grãos de pólen simplesmente 3 -colporados e exina psilada ou quase psilada a granulada, divergindo do espécime aqui analisado que apresentou grãos parassincolporados e exina rugulado-perfurada.

Material estudado: BRASIL. São Paulo: Cotia, 29-IX-2003, G.Y. Saiki s.n. (SP292946).

\section{Eugenia speciosa Cambess.}

Forma: oblata.

Aberturas: 3-colporadas, cólporos irregularmente parassincolporados, endoabertura de difícil visualização.

Exina: rugulado-perfurada, sexina mais delgada que a nexina.

Medidas $(\mu \mathrm{m}): \mathrm{P}=11,9 ; \mathrm{E}=20,5$; eixo equatorial $\mathrm{em}$ vista polar $=20,0 \pm 0,2$; exina ca. 2,0 , sexina ca. 0,8 e nexina ca. 1,1 .

Observações: Barth \& Barbosa (1972) enquadraram os grãos de pólen da espécie no grupo 3. grãos heteropolares, 3-colporados longicolpados e 3-colporados, sincolpados às vezes parassincolporados, com exina granulada a insulada. No presente estudo foram observados apenas grãos isopolares, irregularmente parassincolporadas e com exina rugulado-perfurada.

Material estudado: 16-X-1933, O. Handro s.n. (SP31178).

\section{Eugenia stigmatosa DC.}

Forma: oblata.

Aberturas: 3-(4)-colporadas, cólporos irregularmente parassincolporados, endoabertura de difícil visualização.

Exina: rugulado-perfurada, sexina mais delgada que a nexina.

Medidas $(\mu \mathrm{m}): \mathrm{P}=11,8 ; \mathrm{E}=18,9$; eixo equatorial em vista polar $=19,3 \pm 0,9$; cólporo larg. ca. 1,0; exina ca. 2,1 , sexina ca. 0,8 e nexina ca. 1,3 .

Observações: os espécimes da Reserva, F. Barros 1961 (SP), M.R.O. Santos et al. 30 (SP) citados por Kawasaki (2000) não foram estudados por possuírem apenas frutos. Barth \& Barbosa (1972) enquadraram os grãos de pólen dessas espécies no grupo 2. grãos 3-sincolporados e com exina granulada. O espécime aqui analisado não corrobora a descrição apresentada pelas autoras, já que estes possuem grãos 3-colporados, irregularmente parassincolporados e exina ruguladoperfurada. Barth \& Barbosa (1972) não observaram a presença de grãos raramente 4-colporados.

Material estudado: BRASIL. PARAnÁ: Andorinha, 14-VI-1988, G. Hstschbach \& J.M. Silva 521446 (SP).

Chave para as espécies de Eugenia

1. Grãos de pólen com exina rugulada ou rugulado-perfurada

2. Exina rugulada, cólporos longos, muito longos a parassincolporados

3.3-colporados, passincolporados

E. dodoneifolia

E. neoglomerata

3. 3-colporados, cólporos longos ou muito longos

4. cólporos longos

E. convexinervia

4. cólporos muito longos

E. beaurepairiana

2. Exina rugulado-perfurada, cólporos parassincolporados

E. excelsa

E. handroana

E. neoverucosa

E. punicifolia

E. speciosa

E. stigmatosa

1. Grãos de pólen com exina rugulado-microrreticulada 
5. 4-(5)- colporados, cólporos longos

E. bimarginata

5.3-colporados ou 3-(4)-colporados, cólporos parassincolporados

6. 3-colporados

E. cereja

6. 3-(4)-colporados E. cerasifolia

\section{Gomidesia O. Berg}

Grãos de pólen com forma oblata, âmbito triangular, 3-colporados, cólporos longos a irregularmente parassincolporados, com ou sem fastígio, endoabertura lalongada ou lolongada, exina rugulado-perfurada, rugulado-granulada, sexina mais delgada que a nexina.

\section{Gomidesia affinis (Cambess.) D. Legrand}

Forma: oblata.

Aberturas: cólporos longos, sem fastígio, endoabertura lalongada.

Exina: rugulado-perfurada, sexina mais delgada que a nexina.

Medidas $(\mu \mathrm{m})$ : F.C. Hoehne s.n. (SP27393): $\mathrm{P}=15,5 \pm 0,1 ; \mathrm{E}=22,7 \pm 0,2$; eixo equatorial em vista polar $=21,3 \pm 0,2$; cólporo compr. ca. 10,0, larg. ca. 2,0; endoabertura compr. ca. 2,4, larg. ca. 6,1; exina ca. 1,6, sexina ca. 0,7 e nexina ca. 1,0.

O. Handro s.n. (SP29456): eixo equatorial em vista polar $=21,3$.

S. L. Jung et al. 388 (SP): eixo equatorial em vista polar $=19,9$.

Observações: Barth \& Barbosa (1972) estudaram Gomidesia affinis var. catharinensis D. Legrand e enquadraram seus grãos de pólen do grupo 1. grãos simplesmente 3-colporados, com exina a granulada. $\mathrm{O}$ espécime aqui analisado também apresentou aberturas 3-colporadas, porém a exina possui ornamentação, rugulado-perfurada. De acordo com a Flora do Brasil (2020, em construção) Myrcia hebepetala DC. é o nome aceito para essa espécie atualmente.

Material estudado: 4-IV-1932, O. Handro s.n. (SP29456); 26-III-1931, F.C. Hoehne s.n. (SP27393); 10-VI-1981, S.L. Jung et al. 388 (SP).

\section{Gomidesia anacardiifolia (Gardner) O. Berg}

Aberturas: cólporos irregularmente parassincolporados, sem fastígio, endoabertura lolongada.

Exina: rugulado-perfurada, sexina mais delgada que a nexina.
Medidas $(\mu \mathrm{m}): \mathrm{P}=15,3 \pm 0,1 ; \mathrm{E}=23,3 \pm 0,1$; eixo equatorial em vista polar $=22,8 \pm 0,2$; cólporo compr. ca. 10,2, larg. ca. 2,5; endoabertura compr. ca. 6,9, larg. ca. 2,6; exina ca. 2,1, sexina ca. 0,8 e nexina ca. 1,3 .

Observações: os espécimes da Reserva F.C. Hoehne s.n. (SP28812), M. Sugiyama 519 (SP) citados por Kawasaki (2000) não foram estudados por possuir apenas fruto ou por escassez de material polínico. Barth \& Barbosa (1972) ao estudarem essa espécie enquadraram seus grãos de pólen do grupo 1. grãos simplesmente 3-colporados, com exina granulada. Houve divergência com este trabalho com relação às aberturas já que aqui estes são irregularmente parassincolporados e também com o tipo de ornamentação sendo no espécime aqui analisado rugulado-perfurada. Para a Flora do Brasil (2020, em construção) Myrcia anacardiifolia Gardner é o nome aceito para essa espécie atualmente.

Material estudado: BRASIL. PARANÁ: Paranaguá, 7-III-1990, J.M. Silva 811 (SP).

\section{Gomidesia sellowiana O. Berg}

Figuras 34-35

Aberturas: cólporo longos, sem fastígio, endoabertura lalongada.

Exina: rugulado-granulada, sexina mais delgada que a nexina.

Medidas ( $\mu \mathrm{m}): \mathrm{P}=15,7 \pm 0,2 ; \mathrm{E}=21,0 \pm 0,3$; eixo equatorial em vista polar $=21,4 \pm 0,2$; cólporo compr. ca. 10,6, larg. ca. 1,4; endoabertura compr. ca. 1,3, larg. ca. 6,7; exina ca. 1,7 , sexina ca. 0,7 e nexina ca. 0,9 .

Observações: Barth \& Barbosa (1972) enquadraram seus grãos de pólen no grupo 1. simplesmente 3-colporados, com exina a granulada. O espécime aqui analisado também apresenta aberturas simplesmente 3-colporadas, porém a exina é rugulado-perfurada. Para a Flora do Brasil (2020, em construção) Myrcia hartwegiana (O.Berg) Kiaersk. é o nome aceito para essa espécie atualmente.

Material estudado: 19-II-1932, O. Handro s.n. (SP28807). 
4. Gomidesia tijucensis (Kiaersk.) D. Legrand

Figura 36

Aberturas: cólporos irregularmente parassincolporadas, com fastígio, endoabertura lolongada.

Exina: rugulado-perfurada, sexina mais delgada que a nexina.

Medidas $(\mu \mathrm{m}): \mathrm{P}=13,6 \pm 0,10 ; \mathrm{E}=22,4 \pm 0,1 ;$ eixo equatorial em vista polar $=21,4 \pm 0,2$; cólporo compr. ca. 9,5, larg. ca. 1,8; endoabertura compr. ca. 4,8, larg. ca. 2,1 ; exina ca. 2,3 , sexina ca. 1,1 e nexina ca. 1,4 .
Observações: para Barth \& Barbosa (1972) esta espécie foi enquadrada no grupo 1. simplesmente 3-colporado, com exina a granulada. Os resultados aqui obtidos não corroboram os das referidas autoras já que aqui os cólporos são irregularmente parassincolporados e a exina é rugulado-perfurada. Para a Flora do Brasil (2020, em construção) Myrcia tijucensis Kiaersk. é o nome aceito para essa espécie atualmente.

Material estudado: 4-II-1934, O. Handro s.n. (SP31677).

Chave para as espécies de Gomidesia

1. Grãos de pólen com exina rugulado-granulada, 3-colporados, cólporos longos G. selllowiana

1. Grãos de pólen com exina rugulado-perfurada, 3-colporados, cólporos longos ou 3-parassincolporados

2. 3-colporados, cólporos longos G. afinis

2. 3-parassincolporadas

3. cólporos com fastigio G. tijuscescens

3. cólporos sem fastígio G. anacardiifolia

Marlierea Cambess.

Grãos de pólen com forma oblata, âmbito triangular, 3-colporados, irregularmente parassincolporados, sem fastígio, endoabertura de difícil visualização, exina rugulado-perfurada, sexina da mesma espessura que a nexina ou mais delgada que a nexina.

\section{Marlierea parviflora $\mathrm{O}$. Berg}

Figura 37

Exina: sexina da mesma espessura que a nexina.

Medidas $(\mu \mathrm{m})$ : O. Handro s.n. (SP28406): $\mathrm{P}=15,4 \pm 0,23 ; \mathrm{E}=21,2 \pm 0,30$; eixo equatorial em vista polar $=21,0 \pm 0,2$; exina ca. 1,6 , sexina ca. 0,8 e nexina ca. 0,8 .

M. Kirizawa, 296 (SP): eixo equatorial em vista polar $=18,7$.

Observações: Barth \& Barbosa (1972) estudaram a espécie e caracterizaram seus grãos de pólen no grupo 4. 3-colporados, irregularmente parassincolpadose e exina psilada ou quase psilada. O espécime aqui analisado corroborou com as autoras com relação ao tipo de abertura que aqui também é 3-colporada, irregularmente parassincolporada, porém discordou com relaçao à ornamentação da exina já que aqui esta foi considerada rugulado-perfurada. Segundo a Flora do Brasil (2020, em construção) Marlierea excoriata Mart. é o nome aceito para essa espécie atualmente.

Material estudado: 28-X-1931, O. Handro s.n. (SP28406); 14-X-1977, M. Kirizawa, 296 (SP).

\section{Marlierea racemosa (Vell.) Kiaersk.}

Figura 38

Exina: sexina mais delgada que a nexina

Medidas $(\mu \mathrm{m}): \mathrm{P}=18,0 \pm 0,2 ; \mathrm{E}=24,9 \pm 0,3$; eixo equatorial em vista polar $=24,5 \pm 0,3$; exina ca. 2,2 ; sexina ca. 0,9 e nexina ca. 1,1 .

Observações: Barth \& Barbosa (1972) enquadraram os grãos de pólen dessa espécie no grupo 1. simplesmente 3-colporados com exina granulada. Os resultados aqui obtidos não corroboraram com os das referidas autoras já que neste trabalho os grãos de pólen são 3-colporados, irregularmente parassincolporadas e exina rugulado-perfurada.

Material estudado: 28-XI-1980, S.L. Jung \& F. Barros 369 (SP).

\section{Myrceugenia O. Berg}

1. Myrceugenia rufescens (DC.) D. Legrand \& Kausel Figura 39

Forma: oblata.

Aberturas: 3-colporadas, irregularmente parassincolporadas, sem fastígio, endoabertura de difícil visualização

Exina: areolado-rugulada, sexina mais delgada que a nexina.

Medidas $(\mu \mathrm{m}): \mathrm{P}=11,7 \pm 0,1 ; \mathrm{E}=21,1 \pm 0,2$; eixo equatorial em vista polar $=20,0 \pm 0,2$; cólporo larg. ca. 2,5 ; exina ca. 1,8 , sexina ca. 0,7 e nexina ca. 1,2 . 
Observações: Barth \& Barbosa (1972) estudaram Myrceugenia rufescens var. alegrensis D. Legrand enquadrando seus grãos de pólen no grupo 4 . 3-colporados, irregularmente parassincolpados exina insulada. Os resultados aqui obtidos corroboraram com os das referidas autoras com relação as aberturas 3-colporadas, irregularmente parassincolpadas, presença de fastígio e ornamentação da exina aqui descrita aqui como areolado-rugulada. Ressalta-se que o termo utilizado por Barth \& Barbosa (1972) como insulado é sinônimo de areolado por Punt et al. 2007.

Material estudado: 28-IX-1931, F.C. Hoehne s. $n$. (SP28199).

\section{Myrcia DC.}

Grãos de pólen com âmbito triangular, oblatos; pequenos a médios; 3-(4)-colporados, irregularmente parassincolporados, com ou sem fastígio, endoabertura lalongada ou de difícil visualização; exina, rugulada, rugulado-perfurada, granulada a areolada, sexina mais delgada a mais espessa que a nexina.

\section{Myrcia amazonica DC.}

Figuras 40-42

Forma: oblata.

Aberturas: 3-colporadas, sem fastígio, endoabertura de difícil vizualização.

Exina: areolada, sexina mais delgada que a nexina. Medidas $(\mu \mathrm{m}): \mathrm{P}=14,8 \pm 0,2 ; \mathrm{E}=23,8 \pm 0,3$; eixo equatorial em vista polar $=22,0 \pm 0,2$ exina ca. 1,7 , sexina ca. 0,7 e nexina ca. 1,1 .

Observações: O espécime estudado foi citado por Kawasaki (2000) como Myrcia sp, sendo posteriormente revisado e determinado por P.O. Rose em XI-2011 como Myrcia amazonica e incluído no presente estudo. Barth \& Barbosa (1972) estudaram essa espécie sob o sinônimo Myrcia leptoclada DC. e o enquadrou no grupo 4. com aberturas 3-colporadas, irregularmente parassincolpadas e de superfície psilada ou quase psilada. O presente estudo corroborou parcialmente com os dados apresentados pelas autoras com relação ao tipo de abertura, entretanto difere quanto à ornamentação da exina, sendo aqui descrita como areolada.

Material estudado: 11-XI-1970, T. Sendulsky 1159 (SP).

2. Myrcia citrifolia (Aubl.) Urb.

Figuras 43-45
Forma: oblata.

Aberturas: 3-colporadas, sem fastígio, endoabertura de difícil visualização.

Exina: areolada, sexina mais delgada que a nexina.

Medidas $(\mu \mathrm{m}): \mathrm{P}=14,9 \pm 0,2 ; \mathrm{E}=22,5 \pm 0,3$; eixo equatorial em vista polar $=21,3 \pm 0,3$; exina ca. 1,8 , sexina ca. 0,7 e nexina ca. 1,1 .

Observações: Os espécimes da reserva M. Kuhlmann 3343 e E. Kuhn s.n., (SP234573), citados por Kawasaki (2000), não foram estudados por possuírem apenas frutos.

Material estudado: 16-III-1931, O. Handro s.n. (SP28610).

\section{Myrcia fallax (Rich.) DC.}

Figuras 46-47

Forma: oblata.

Aberturas: 3-(4)-colporadas, sem fastígio, endoabertura lalongada.

Exina: granulada.

Medidas $(\mu \mathrm{m}): \mathrm{P}=15,2 \pm 0,2 ; \mathrm{E}=23,4 \pm 0,2 ;$ eixo equatorial em vista polar $=21,1 \pm 0,3$; colpo compr. ca. 7,1, larg. ca.1,0, endoabertura compr. ca. 1,9, larg. ca. 4,7; exina ca.1,8, sexina ca. 0,7 e nexina ca. 1,1 .

J. Mattos 9089 (SP): eixo equatorial em vista polar $=21,3$.

F. Barros 1935 (SP): eixo equatorial em vista polar $=20,5$.

J. S. Silva 344 (SP): eixo equatorial em vista polar $=22,3$.

S. A. C. Chiea 257 (SP): eixo equatorial em vista polar $=21,4$.

S. A. C. Chiea 421 (SP): eixo equatorial em vista polar $=20,8$.

S. L. Jung 401 et al. (SP): eixo equatorial em vista polar $=21,5$.

S.L. Jung 269 et al. (SP): eixo equatorial em vista polar $=20,6$.

Observações: O espécime Myrcia fallax SP 169402 não pôde ser estudado devido à falta de material polínico após o processo de acetólise. Do ponto de vista taxonômico (Souza \& Lorenzi, 2005) ressaltaram a dificuldade de separar Myrcia fallax de Myrcia rostrata, entretanto no presente estudo foi possível 

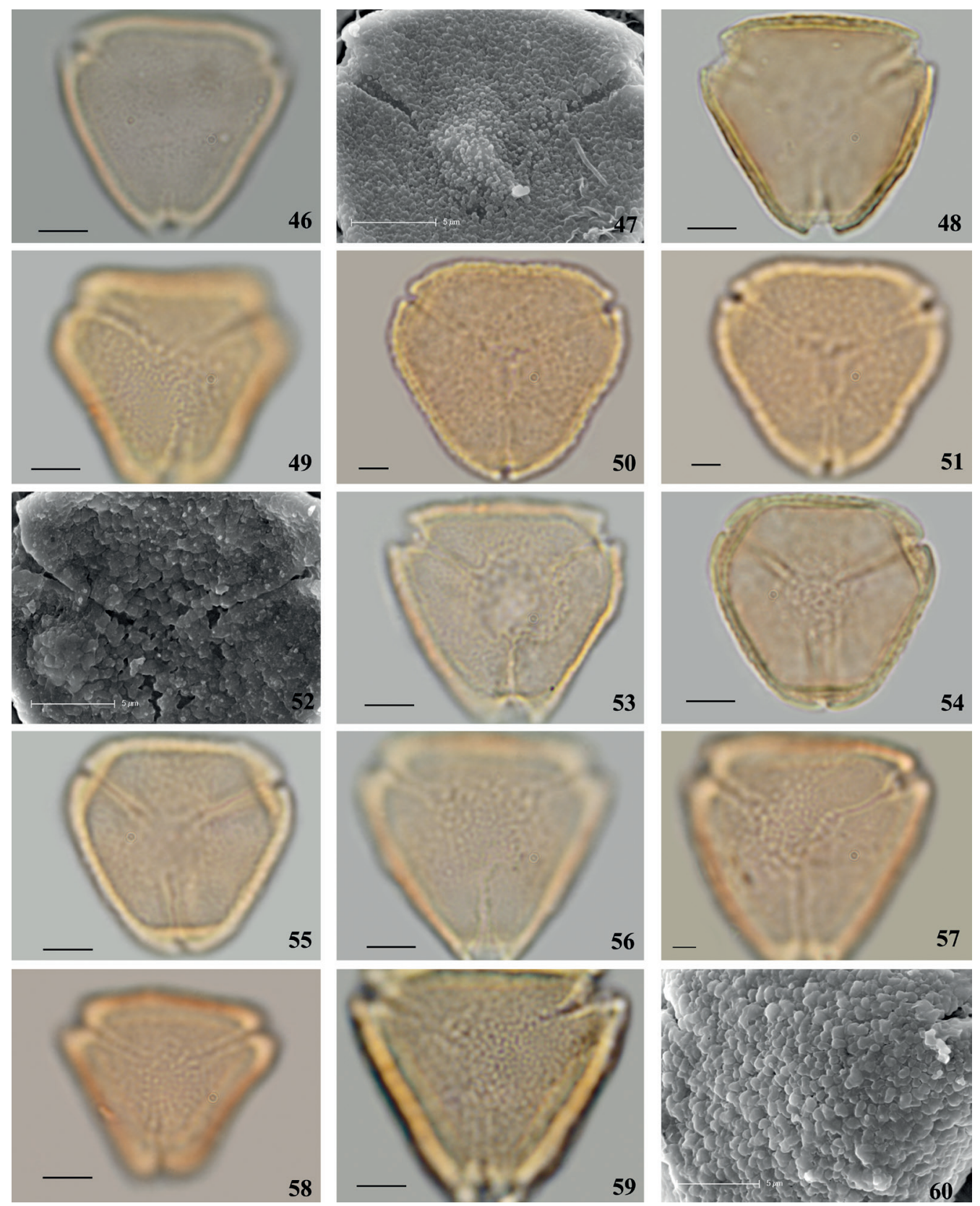

Figuras 46-60. Fotomicrografias dos grãos de pólen de Myrtaceae. 46-47. Myrcia fallax (Rich.) DC. 46. Vista polar evidenciando a ornamentação 47. Detalhe da ornamentação em vista polar. 48-49. Myrcia guianensis (Aubl.) DC. 48. Vista polar, contorno. 49. Vista polar evidenciando a ornamentação. 50-51. Myrcia laruotteana Cambess. 50. Vista polar, contorno. 51. Vista polar evidenciando a ornamentação. 52. Myrcia laxiflora Cambess. Detalhe da ornamentação em vista polar. 53. Myrcia macrocarpa DC. Vista polar evidenciando a ornamentação. 54-55. Myrcia multiflora (Lam.) DC. 54. Vista polar, contorno. 55. Vista polar evidenciando a ornamentação. 56. Myrcia pubipetala Miq. Vista polar evidenciando a ornamentação. 57. Myrcia retorta Cambess. Vista polar evidenciando a ornamentação. 58. Myrcia rostrata DC. Vista polar evidenciando a ornamentação. 59-60. Myrcia tenuivenosa Kiaersk. 59 Vista polar evidenciando a ornamentação. 60. Detalhe da ornamentação em vista polar. Escala: figuras 46-60 $=5 \mu \mathrm{m}$.

Figures 46-60. Photomicrographs and scanning electron micrographs (SEM) of Myrtaceae pollen grains. 46-47. Myrcia fallax (Rich.) DC. 46. Polar view showing the ornamentation. 47. Detail of the ornamentation. 48-49. Myrcia guianensis (Aubl.) DC. 48. Polar view, outline. 49. Polar view showing the ornamentation. 50-51. Myrcia laruotteana Cambess. 50. Polar view, outline. 51. Polar view showing the ornamentation. 52. Myrcia laxiflora Cambess. Polar view showing the ornamentation. 53. Myrcia macrocarpa DC. Polar view showing the ornamentation. 54-55. Myrcia multiflora (Lam.) DC. 54. Polar view, outline. 55. Polar view showing the ornamentation. 56. Myrcia pubipetala Miq. Polar view showing the ornamentation. 57. Myrcia retorta Cambess. Polar view showing the ornamentation. 58. Myrcia rostrata DC. Polar view showing the ornamentation. 59-60. Myrcia tenuivenosa Kiaersk. 59. Polar view showing the ornamentation. 60. Polar view showing the ornamentation. Scale: figures 46-60 $=5 \mu \mathrm{m}$. 
separá-las quanto ao tipo de ornamentação, já que a primeira espécie apresentou exina granulada e a segunda exina rugulada. Para a Flora do Brasil (2020, em construção) Myrcia splendens (Sw.) DC. é o nome aceito para essa espécie atualmente.

Material estudado: 30-X-1990, F. Barros 1935 (SP); 5-X-1982, S.A.C. Chiea 257 (SP); 29-VIII-1985, S.A.C. Chiea 421 (SP); 30-IX-1931, F.C. Hoehne s.n. (SP28303); 19-IX-1978, S.L. Jung 269 (SP); 21 X-1981, S.L. Jung 401 (SP); 19-IX-1961, J.Mattos 9089 (SP); 23-X-1968 T. Sendulsky 917 (SP); 10VIII-1974, J.S. Silva 344 (SP); 26-IX-1979, M.S.F. Silvestre 211 (SP).

\section{Myrcia guianensis (Aubl.) DC.}

Figuras 48-49

Forma: oblata.

Aberturas: 3-colporadas, sem fastígio, endoabertura lalongada.

Exina: rugulada, sexina mais delgada que a nexina. Medidas $(\mu \mathrm{m}): \mathrm{P}=17,3 \pm 0,7 ; \mathrm{E}=24,1 \pm 0,2$; eixo equatorial em vista polar $=22,7 \pm 0,2$; colpo compr. ca. 8,5 , larg. ca.1,3; endoabertura compr. ca. 0,9 , larg. ca.5,6; exina ca. 1,9 , sexina ca. 0,7 e nexina ca. 1,2 . M. Kuhlmann 2724 (SP): eixo equatorial em vista polar $=22,0$

Observações: Lieu \& Melhem (1973) ao estudarem os grãos de pólen da espécie sob o nome de Myrcia lingua (O. Berg) Mattos \& D. Legrand relataram a presença de 4 cólporos, longicolpados, já no presente estudo estes não apresentaram 4 aberturas, sendo que estas variaram de longicolpadas a irregularmente parassincolpadas. Quanto à forma e ao tamanho dos grãos de pólen, este estudo corrobora com os dados apresentados pelas referidas autoras, mas difere com relação à ornamentação da exina sendo psilada por Lieu \& Melhem (1973) e rugulada neste trabalho.

Material estudado: 10-VIII-1931, F.C. Hoehne s.n. (SP28133); 4-X-1951, M. Kuhlmann 2724 (SP).

\section{Myrcia laruotteana Cambess.}

Figuras 50-51

Forma: oblata.

Aberturas: 3-colporadas, sem fastígio, endoabertura de difícil visualização.

Exina: areolada, sexina mais delgada que a nexina. Medidas $(\mu \mathrm{m}): \mathrm{P}=16,4 \pm 0,3 ; \mathrm{E}=23,9 \pm 0,3$; eixo equatorial em vista polar $=22,9 \pm 0,1$; exina ca. 1,9 , sexina ca. 0,6 e nexina ca. 1,3 .

Observações: Barth \& Barbosa (1972) ao estudarem Myrcia laruotteana var. australis D. Legrand enquadraram seus grãos de pólen no grupo 3 . heteropolares, com aberturas 3-longicolporadas e 3 -sincolporadas as vezes 3-parassincolporadas com exina granulado-insulada. As autoras ressaltaram a presença de aberturas (3-)4(-5)-colporadas nas proporções 28-66-6\%, respectivamente; o que também não foi observado no espécime aqui analisado. Os resultados aqui obtidos não corroboraram com os das referidas autoras com relação a heteropolaridade dos grãos e ao número de aberturas já que aqui estes são isopolares, irregularmente 3-parassincolporados, entretanto corroborou quanto à ornamentação da exina aqui descrita como areolada, termo este, sinônimo de insulado para Punt et al. 2007.

Material estudado: 20-X-1938, O. Handro s.n. (SP40274).

\section{Myrcia laxiflora Cambess.}

Figura 52

Forma: oblata.

Aberturas: 3-colporadas, sem fastígio, endoabertura de difícil visualização.

Exina: areolada, sexina mais delgada que a nexina. Medidas $(\mu \mathrm{m}): \mathrm{P}=18,0 \pm 0,3 ; \mathrm{E}=26,3 \pm 0,5$; eixo equatorial em vista polar $=23,3 \pm 0,3$; exina ca. 1,7 , sexina ca. 0,6 e nexina ca. 1,1 .

Material estudado: 3-I-1946, M. Kuhlmann s.n. (SP30802).

\section{Myrcia macrocarpa DC.}

Figura 53

Forma: oblata.

Aberturas: 3-colporadas, sem fastígio, endoabertura de difícil visualização.

Exina: rugulado-perfurada.

Medidas $(\mu \mathrm{m}): \mathrm{P}=15,7 \pm 0,6 ; \mathrm{E}=23,0 \pm 0,5 ;$ eixo equatorial em vista polar $=23,1 \pm 0,2$; exina ca. 1,5 , sexina ca. 0,6 e nexina ca. 1,0 .

R. Faria 8 (SP): eixo equatorial em vista polar $=22,2$. Material estudado: 25-III-1965, R. Faria 8 (SP); 18-IV-1961, J. Mattos 8889 (SP).

8. Myrcia multiflora (Lam.) DC.

Figuras 54-55 
Forma: oblata.

Aberturas: 3-(4)-colporadas, com fastígio, endoabertura de difícil visualização.

Exina: areolada, sexina mais delgada que a nexina. Medidas $(\mu \mathrm{m}): \mathrm{P}=16,1 \pm 0,3 ; \mathrm{E}=24,7 \pm 0,3$; eixo equatorial em vista polar $=23,4 \pm 0,3$; exina ca.1,9, sexina ca. 0,8 e nexina ca. 1,2 .

O. Handro s.n. (SP28409): eixo equatorial em vista polar $=22,2$.

F. C. Hoehne s.n.(SP28315): eixo equatorial em vista polar $=21,8$.

R. Faria \& O. G. Fonseca s.n. (SP99429): eixo equatorial em vista polar $=22,4$.

S. A. C. Chiea 137 (SP): eixo equatorial em vista polar $=21,1$.

J. S. Silva 06 (SP): eixo equatorial em vista polar $=21,2$.

F. C. Hoehne s.n. (SP25028): eixo equatorial em vista polar $=21,8$.

F. Barros 1942 (SP): eixo equatorial em vista polar $=20,6$.

Observações: o espécime da reserva F.C. Hoehne s.n. (SP32553) não foi estudado por estar representado apenas por fruto. Barth \& Barbosa (1972), ao estudarem os grãos de pólen de Myrcia multiflora var. glaucescens for. glaucescens (O. Berg) D.Legrand os enquadraram no grupo 4. 3-colporados, irregularmente parassincolpados e exina com aspecto insulado. No presente estudo a espécie apresentou grãos 3-(4)-colporados e ornamentação areolada.

Material estudado: 14-XI-1990, F. Barros 1942 (SP); 5-XI-1980, S.C.A. Chiea 137 (SP); 23-XI-1966, R. Farias \& O.G. Fonseca s.n.(SP99429); 28-X-1931, O. Handro s.n. (SP28409); 25-XI-1930, F.C. Hoehne s.n. (SP25028); 30-XI-1931, F.C. Hoehne s.n. (SP28315); 28-X-1968, J. Mattos 15384 (SP); 13-II-1972, J.S. Silva 6 (SP).

\section{Myrcia pubipetala Miq.}

Figura 56

Forma: oblata.

Aberturas: 3-colporadas, sem fastígio, endoabertura lalongada.

Exina: areolada, sexina mais delgada que a nexina.

Medidas $(\mu \mathrm{m}): \mathrm{P}=16,0 \pm 0,2 ; \mathrm{E}=26,2 \pm 0,3$; eixo equatorial em vista polar $=25,9 \pm 0,2$; cólporo larg. ca.1,8; endoabertura compr. ca. 3,4, larg. ca.8,0; exina ca. 1,8 , sexina ca. 0,7 e nexina ca. 1,2.

O. Handro s.n. (SP50385): eixo equatorial em vista polar $=24,1$.

Observações: os grãos de pólen de dois espécimes de Myrcia pubipetala var. pubipetala foram analisados por Barth \& Barbosa (1972) que os enquadraram no grupo 1. simplesmente 3-colporados de superfície insulada. Os resultados apresentados pelas autoras confirmam os dados aqui obtidos quanto ao tipo de abertura e quanto à ornamentação da exina.

Material estudado: 27-II-1946, O. Handro s.n. (SP 50385); 22-III-1938 F.C. Hoehne s.n. (SP39250).

\section{Myrcia pulchra (O. Berg) Kiaersk.}

Forma: oblata.

Aberturas: 3-colporadas, sem fastígio, endoabertura de difícil visualização.

Exina: areolada, sexina mais delgada que a nexina.

Medidas ( $\mu \mathrm{m}): \mathrm{P}=16,1 \pm 0,3 ; \mathrm{E}=23,6 \pm 0,3$; eixo equatorial em vista polar $=23,4 \pm 0,3$; exina ca. 1,6 , sexina ca. 0,6 e nexina ca. 1,0 .

Observações: Myrcia pulchra foi estudada por Barth \& Barbosa (1972) sob o sinônimo Myrcia breviramis (O. Berg) D. Legrand. As autoras enquadraram a espécie no grupo 1. simplesmente 3-colporados, com fastígio e de superfície insulada. Os resultados do presente estudo corroboraram parcialmente os das referidas autoras, já que neste trabalho as aberturas 3-colporadas não apresentaram fastígio, entretanto quanto a ornamentação a da exina houve concordância. Segundo a Flora do Brasil (2020, em construção) Myrcia subcordata DC. é o nome aceito para essa espécie atualmente.

Material estudado: 14-XII-1932, O.Handro s.n (SP29982).

\section{Myrcia retorta Cambess.}

Figura 57

Forma: oblata.

Aberturas: 3-colporadas, sem fastígio, endoabertura lalongada.

Exina: rugulada, sexina mais delgada que nexina.

Medidas ( $\mu \mathrm{m}): \mathrm{P}=18,0 \pm 0,3 ; \mathrm{E}=25,7 \pm 0,3$; eixo equatorial em vista polar $=24,9 \pm 0,3$; cólporo larg. ca. 1,7; endoabertura compr. ca. 4,1, larg. ca. 8,0; exina ca. 1,9 , sexina ca. 0,7 e nexina ca. 1,2 . 
Observações: Barth \& Barbosa (1972) estudaram Myrcia retorta sob o sinônimo Myrcia arborescens O. Berg. As autoras enquadraram a espécie no grupo 4. com aberturas 3-colporadas, irregularmente parassincolporadas com fastígio e exina psilada ou quase psilada. O presente estudo, não corroborou os resultados das autoras já que aqui as aberturas não são parassincolporadas, não apresentaram fastígio e a superfície foi descrita como rugulada.

Material estudado: 14-X-1938, O. Handro s.n. 14-X1938 (SP40275).

\section{Myrcia rostrata DC. \\ Figura 58}

Forma: oblata.

Aberturas: 3-(4)-colporadas, sem fastígio, endoabertura lalongada.

Exina: rugulada, sexina mais delgada que a nexina. Medidas $(\mu \mathrm{m}): \mathrm{P}=14,1 \pm 0,2 ; \mathrm{E}=20,4 \pm 0,2$; eixo equatorial em vista polar $=19,8 \pm 0,2 ;$ cólporo larg. ca. 1,7; endoabertura compr. ca. 1,9, larg. ca. 6,0; exina ca. 1,9, sexina ca. 0,7 e nexina ca. 1,2.

Observações: Barth \& Barbosa (1972) analisaram dois espécimes de Myrcia rostrata fo. gracilis (O. Berg) D. Legrand e enquadraram seus grãos de pólen no grupo 1. com aberturas simplesmente 3-colporadas, com fastígio e superfície granulada. Os resultados aqui obtidos divergiram dos das autoras já que aqui estes são irregularmente parassincolporados, sem fastígio. Quanto a exina, o espécime aqui observado apresentou exina rugulada, enquanto os de Barth \& Barbosa (1972) são granulados. Para Lieu \& Melhem (1973) os grãos de pólen de $M$. rostrata são parassincolpados e com ornamentação psilada. O presente estudo corroborou apenas quanto ao tipo de abertura, já que a exina aqui foi definida como rugulada. Segundo a Flora do Brasil (2020, em construção) Myrcia splendens (Sw.) DC. é o nome aceito para essa espécie atualmente.

Material estudado: XI-1932, O. Handro s.n. (SP29922).

\section{Myrcia tenuivenosa Kiaersk.}

Figuras 59-60.

Forma: oblata.

Aberturas: 3-colporadas, sem fastígio, endoabertura lalongada.

Exina: areolada, sexina mais espessa que a nexina.

Medidas $(\mu \mathrm{m}): \mathrm{P}=17,7 \pm 0,3 ; \mathrm{E}=26,3 \pm 0,3$; eixo equatorial em vista polar $=24,5 \pm 0,3$; cólporo ca. 1,0 ; endoabertura compr. ca. 1,5, larg. ca. 5,1; exina ca. 2,3 , sexina ca. 1,3 e nexina ca. 1,1

Observações: a espécie foi analisada por Barth \& Barbosa (1972) que enquadraram seus grãos de pólen no grupo 1. com aberturas simplesmente 3-colporadas, com fastígio e superfície insulada. Os resultados aqui obtidos não corroboraram os das referidas autoras quanto ao tipo de abertura já que aqui, estas são parassincolporadas entretanto concordou quanto a ornamentação da exina.

Material estudado: 6-XI-1945, M. Kulhmann 2822 (SP).

14. Myrcia tomentosa (Aubl.) DC.

Figuras 61-62

Forma: oblata.

Aberturas: 3-colporadas, sem fastígio, endoabertura lalongada.

Exina: rugulada, sexina mais delgada que a nexina.

Medidas $(\mu \mathrm{m}): \mathrm{P}=13,8 \pm 0,2 ; \mathrm{E}=20,7 \pm 0,2$; eixo equatorial em vista polar $=19,8 \pm 0,2$; cólporo larg. ca.1,2; endoabertura compr. ca. 1,6, larg. ca. 5,3; exina ca.1,6, sexina ca. 0,6 e nexina ca. 0,9 .

O. Handro s. $n$. (SP42950): eixo equatorial em vista polar $=19,6$.

M. Kirizawa 285 (SP): eixo equatorial em vista polar $=21,0$.

Observações: Barth \& Barbosa (1972), estudaram a espécie sob o sinônimo Myrcia floribunda Miq. e enquadraram seus grãos de pólen no grupo1. com aberturas simplesmente 3-colporadas, com fastígio e exina granulada, já no presente trabalho estes são irregularmente parassincolpados e exina rugulada. Para Lieu \& Melhem (1973), esta espécie apresentou grãos de pólen longicolporados e ornamentação psilada.

Material estudado: 28-X-1931, O. Handro s.n. (SP28407); 22-XI-19-38, O. Handro s.n. (SP42950); 15-IX-1977, M. Kirizawa 285 (SP).

\section{Myrcia venulosa DC.}

Figuras 63-65

Forma: oblata.

Aberturas: 3-colporadas, sem fastígio, endoabertura lalongada. 

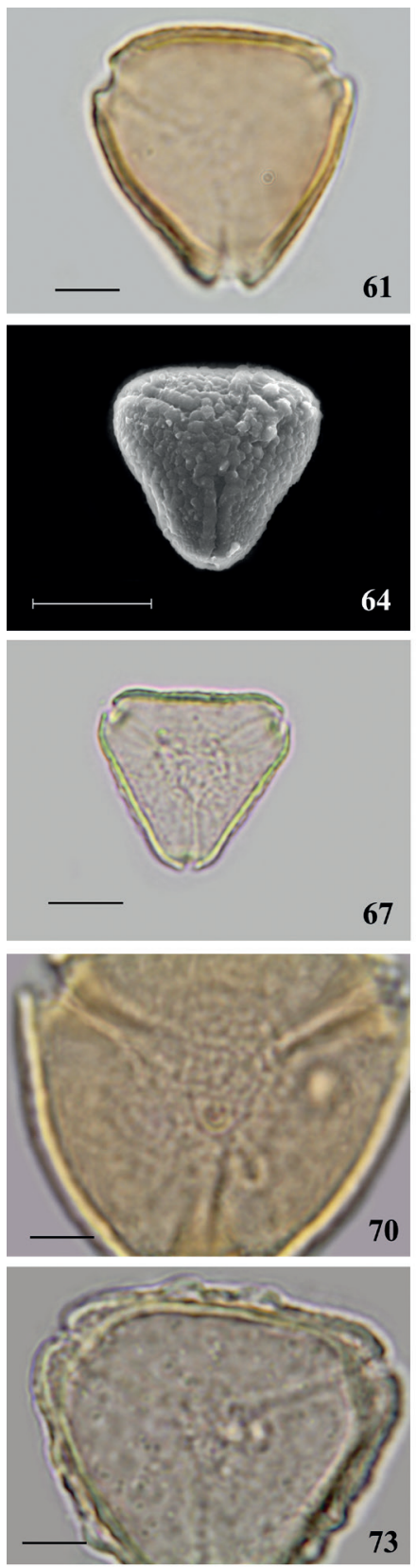

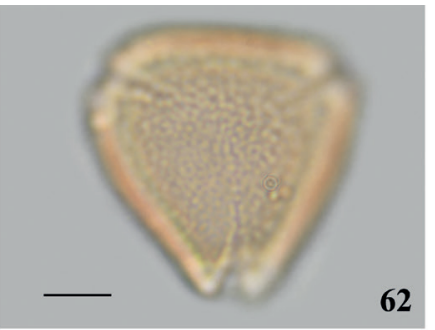

62
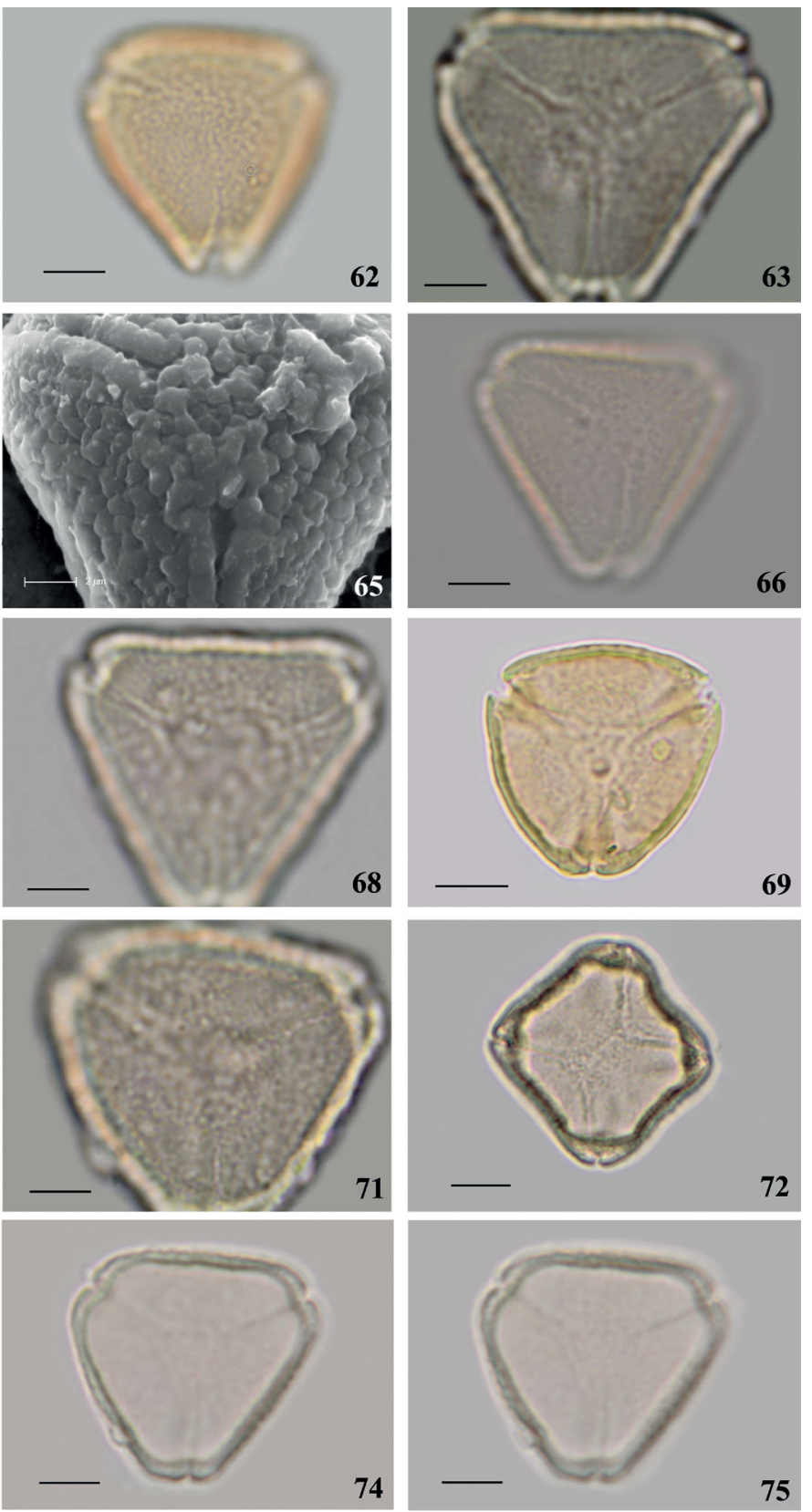

Figuras 61-75. Fotomicrografias e eletron-micrografias (MEV) dos grãos de pólen de Myrtaceae. 61-62. Myrcia tomentosa (Aubl.) DC. 61. Vista polar, contorno. 62. Vista polar evidenciando a ornamentação. 63-65. Myrcia venulosa DC. 63. Vista polar evidenciando a ornamentação. 64. Aspecto geral em vista polar. 65. Detalhe da ornamentação em vista polar. 66. Myrciaria floribunda (West ex Willd.). Vista polar evidenciando a ornamentação. 67-68. Pimenta pseudocaryophyllus (Gomes) Landrum. 67. Vista polar, contorno. 68. Vista polar evidenciando a ornamentação. 69-70. Psidium cattleyanum Sabine. 69. Vista polar, contorno. 70. Vista polar evidenciando a ornamentação. 71-73. Psidium guineense Sw. 71. Vista polar evidenciando a ornamentação. 72. Vista polar de um grão com quatro aberturas. 73. Corte óptico em vista polar. 74-75. Siphoneugena widgreniana O. Berg. 74. Vista polar, contorno. 75. Vista polar evidenciando a ornamentação. Escala: figuras 64, 69, 72 = $10 \mu \mathrm{m}$; figura $65=2 \mu \mathrm{m}$; figuras $61,62,63,66,67,68,70,71,73,74,75=5 \mu \mathrm{m}$.

Figures 61-75. Photomicrographs and scanning electron micrographs (SEM) of Myrtaceae pollen grains. e61-62. Myrcia tomentosa (Aubl.) DC. 62. Polar view, outline. 62. Polar view showing the ornamentation. 63-65. Myrcia venulosa DC. 63. Polar view showing the ornamentation. 64. Polar overview.65. Polar view showing the ornamentation. 66. Myrciaria floribunda (H. West ex Willd.). Polar view showing the ornamentation. 67-68. Pimenta pseudocaryophyllus (Gomes) Landrum. 67. Polar view, outline. 68. Polar view showing the ornamentation. 69-70. Psidium cattleyanum Sabine. 69. Polar view, outline. 70. Polar view showing the ornamentation. 71-73. Psidium guineense Sw. 71. Polar view showing the ornamentation. 72. Polar view of the pollen grain showing four apertures. 73. Polar view, optical section. 74-75. Siphoneugena widgreniana O. Berg. 74. Polar view, outline. 75. Polar view showing the ornamentation. Scale: figures $64,69,72=10 \mu \mathrm{m}$; figure $65=2 \mu \mathrm{m}$; figures $61,62,63,66,67,68,70,71,73,74,75=5 \mu \mathrm{m}$. 
Exina: areolada, sexina mais delgada que a nexina.

Medidas $(\mu \mathrm{m}): \mathrm{P}=16,4 \pm 0,3 ; \mathrm{E}=25,6 \pm 0,3$; eixo equatorial em vista polar $=23,7 \pm 0,3$; cólporo larg. ca.1,9; endoabertura compr. ca. 3,2, larg. ca.8,4; exina ca. 1,9 , sexina ca. 0,8 e nexina ca. 1,2 .

O. Handro, s.n. (SP29923): eixo equatorial em vista polar $=25,4$

Observações: Barth \& Barbosa (1972), estudaram essa espécie sob o sinônimo Myrcia castrensis (O.
Berg) D. Legrand e enquadraram seus grãos de pólen no grupo 1. simplesmente 3-colporados, com fastígio e superfície insulada. No presente estudo, todas as espécies de Myrcia apresentaram aberturas irregularmente parassincolporadas, e em especial $M$. venulosa não apresentou fastígio, discordando dos resultados apresentados pelas autoras. Quanto à ornamentação da exina também houve concordância.

Material estudado: 21-XI-1932, O. Handro, s.n. (SP29923); 26-XI-1930, F.C. Hoehne s.n. (SP26692).

Chave para as espécies de Myrcia

1. Grãos de pólen com exina granulada

M. fallax

1. Grãos de pólen com exina rugulado-perfurada ou areolada

2. Grãos de pólen com exina rugulado-perfurada

M. guianensis

M. laxiflora

M. macrocarpa

M. retorta

M. rostrata

M. tomentosa

2. Grãos de pólen com exina areolada

3. Grãos de pólen com fastígio

M. laruotteana

M. multiflora

3. Grãos de pólen sem fastígio

4. Grãos de pólen com espessura da exina $\geq 2 \mu$ m exina ca. $2,33 \mu \mathrm{m}$

M. tenuivenosa

4. Grãos de pólen com espessura da exina $<2 \mu \mathrm{m}$ M. amazonica M. citrifolia M. pubipetala M. pulchra M. venulosa

\section{Myrciaria O. Berg}

Grãos de pólen com âmbito triangular, oblatos; pequenos; 3-colporados, cólporos longos a irregularmente parassincolporados, sem fastígio, endoabertura lolongada ou de difícil visualização; exina, rugulada a areolada, sexina mais delgada que a nexina.

\section{Myrciaria delicatula (DC.) O. Berg}

Forma: oblata.

Aberturas: cólporos longos, endoabertura lolongada.

Exina: rugulada, sexina mais espessa que nexina.

Medidas $(\mu \mathrm{m})$ : F.C. Hoehne s.n. (SP27395): $\mathrm{P}=14,2 \pm 0,1 ; \mathrm{E}=20,8 \pm 0,1 ;$ eixo equatorial em vista polar $=19,5 \pm 0,3$; cólporo compr. ca. 8,8, larg. ca. 2,0; endoabertura compr. ca. 5,5, larg. ca. 2,1; exina ca. 2,3; sexina ca. 1,1 e nexina ca. 1,3.
M. Kuhlmann s.n. (SP47403): eixo equatorial em vista polar $=23,3$.

F.C. Hoehne s.n. (SP26501): eixo equatorial em vista polar $=18,6$.

J. Mattos 13461: eixo equatorial em vista polar $=16,4$.

Observações: os espécimes da Reserva Hoehne s.n. (SP28645), M. Kuhlmann 2730 (SP), T. Sendulsky 945 (SP), citados por Kawasaki (2000), não foram estudados por estarem em fruto. Barth \& Barbosa (1972) observaram essa espécie e enquadraram seus grãos de pólen no grupo 2. com aberturas 3-colporadas, sincolporadas, com fastígio e exina granulada. Os resultados aqui obtidos para a espécie não corroboraram com os das referidas autoras já que aqui estes são 3-colporados, cólporos longos e com exina rugulada.

Material estudado: 12-V-1930, F.C. Hoehne s.n. (SP26501); 26-III-1931, F.C. Hoehne s.n. (SP27395); 
III-1942, M. Kuhlmann s.n. (SP47403); 2-II-1965, J. Mattos 13461 (SP).

\section{Myrciaria floribunda (H. West ex Willd.) O. Berg} Figura 66

Forma: oblata.

Aberturas: cólporos irregularmente parassincolporados, endoabertura difícil visualização.

Exina: areolada, sexina mais delgada que a nexina.

Medidas $(\mu \mathrm{m}): \mathrm{P}=14,2 \pm 0,1 ; \mathrm{E}=19,1 \pm 0,2$; eixo equatorial em vista polar $=18,4 \pm 0,2$; exina ca. 1,7 ; sexina ca. 0,7 e nexina ca.1,0.

O. Handro s.n. (SP29304): eixo equatorial em vista polar $=17,5$

Observações: o espécime da Reserva $O$. Handro s.n. (S47310), citado por Kawasaki (2000), não foi estudado por se encontrar em fruto. Barth \& Barbosa (1972) ao analisarem a espécie enquadraram seus grãos de pólen no grupo 1. aberturas simplesmente 3-colporadas com fastígio e exina granulada. Houve divergência com os resultados apresentados pelas autoras já que neste trabalho as aberturas são irregularmente parassincolporados e exina areolada.

Material estudado: 19-III-1932, O. Handro s.n. (SP29304); III-1942, O. Handro s.n. (SP47286).

Chave para as espécies de Myrciaria

1. Grãos de pólen com exina areolada 3-parassincolporados ................... Myrci.floribunda

1. Grãos de pólen com exina rugulada,

3-cólporos longos Myrci. delicatula

Pimenta Lindl.

\section{Pimenta pseudocaryophyllus (Gomes) Landrum}

Figuras 67-68

Forma: oblata.

Aberturas: 3-colporadas, cólporos irregularmente parassincolporados, sem fastígio, endoabertura de difícil visualização.

Exina: areolada, sexina mais delgada que a nexina.

Medidas $(\mu \mathrm{m}): \mathrm{P}=16,1 \pm 0,2 ; \mathrm{E}=22,3 \pm 0,3$; eixo equatorial em vista polar (grãos de pólen maiores) $=$ $23,1 \pm 0,2$; exina ca. 1,7 , sexina ca. 0,8 e nexina ca. 1,0 .

Observações: os espécimes da Reserva $O$. Handro 454 (SP), M. Kuhlmann 3354 (SP) e J. Mattos 13462 (SP), citados por Kawasaki (2000), não foram estudados por estarem em fruto. Nesta espécie ocorreram tamanhos de grãos de pólen distintos, variando de pequenos a médios. Pode-se obter o resultado de $55 \%$ de grãos de pólen de tamanho pequeno e $45 \%$ de grãos de pólen de tamanho grande.

Material estudado: 11-XII-1931, O. Handro, s.n. (SP26658).

\section{Psidium L.}

Grãos de pólen com âmbito triangular a quadrangular, oblatos, 3-(4)-colporados, irregularmente parassincolporados, com fastígio, endoabertura circular ou de difícil visualização; exina areolada, sexina mais delgada a mais espessa que a nexina.

\section{Psidium cattleyanum Sabine}

Figuras 69-70

Exina: sexina mais delgada que a nexina.

Medidas $(\mu \mathrm{m}): \mathrm{P}=21,6 \pm 0,5 ; \mathrm{E}=31,2 \pm 0,6$; eixo equatorial em vista polar $=29,4 \pm 0,4$, exina ca. 1,7 , sexina ca. 0,7 e nexina ca. 1,0 .

Observações: o espécime da Reserva M. Kuhlmann 2835 (SP), citado por Kawasaki (2000), não foi estudado por se encontrar em fruto. Barth \& Barbosa (1972), estudaram dois espécimes sob o sinônimo Psidium littorale Raddi. e posicionaram seus grãos de pólen no grupo 1. aberturas simplesmente 3-(4)-colporadas, com fastígio e exina granulada (Reitz e Klein 1260) a insulada (Eq. Ecologia 171). As observações feitas pelas autoras confirmaram o tipo apertural e a presença de grãos de pólen 4-colporados nessa espécie, entretanto divergiram apenas quanto à ornamentação da exina do espécime Reitz $e$ Klein 1260 por elas analisadas que foi considerada granulada. Tornhill et al. (2012) descreveram os grãos de pólen dessa espécie como oblato-esferoidais, 3-colporados, brevicolpados e exina psilada. O espécime aqui analisado não corroborou os resultados apresentados pelos autores com relação a forma, às aberturas e a ornamentação da exina. Tuler et al. (2016) ao analisarem os grãos de pólen da espécie sob MO e sob MEV, os descreveram como sendo 3-4-parassincolporados, endoabertura lalongada e exina rugulada no mesocolpo e areolada no apocolpo. Os resultados aqui obtidos corroboraram com os das referidas autoras, entretanto aqui não foi possível observar a ornamentação da exina em dois pontos dos 
grãos de pólen já que aqui os mesmos foram descritos somente em MO.

Material estudado: 18-XII-1931, F.C. Hoehne s.n. (SP28609).

\section{Psidium cinereum Mart. ex DC.}

Exina: sexina mais delgada que a nexina

Medidas $(\mu \mathrm{m}): \mathrm{P}=19,2 \pm 0,5 ; \mathrm{E}=28,1 \pm 0,7$; eixo equatorial em vista polar $=27,1 \pm 0,4$, exina ca. 1,8 , sexina 0,7 ca e nexina ca. 0,9 .

Observações: Barth \& Barbosa (1972), estudaram essa espécie sob o sinônimo Psidium incanescens Mart. ex DC. e posicionaram seus grãos de pólen no grupo 3. heteropolares, 3-colporados, longicolpados e 3-sincolporados às vezes parassincolpados com fastígio, e exina granulada a insulada. As autoras relataram a presença de $44 \%$ de grãos 4 -colporados. Os resultados aqui obtidos corroboraram parcialmente com os de Barth \& Barbosa (1972), levando-se em consideração que aqui os grãos não são heteropolares e sim isopolares. Para a Flora do Brasil (2020, em construção) Psidium grandifolium Mart. ex DC. é o nome aceito para essa espécie atualmente.

Material estudado: 10-XI-1940, O. Handro s.n. (SP32819).

\section{Psidium guineense Sw.}

Figuras $72-73$

Abertura: com fastígio

Exina: sexina mais espessa que a nexina

Medidas $(\mu \mathrm{m}): \mathrm{P}=21,0 \pm 0,2 ; \mathrm{E}=31,4 \pm 0,4$; eixo equatorial em vista polar $=28,3 \pm 0,3$; exina ca. 1,9 sexina ca 1,1 e nexina ca. 0,9 .

Observações: o mesmo ocorre para essa espécie quando Tuler et al. (2016) descreveram os grãos de pólen dessa espécie como 3-4-parassincolporado, endoabertura lalongada e exina granulada no mesocolpo e rugulada no apocolpo. Os resultados aqui obtidos corroboraram com os das referidas autoras, entretanto aqui não foi possível observar a ornamentação da exina em dois pontos dos grãos de pólen como explicado anteriormente.

Material estudado: 10-XI-1940, O. Handro,s.n. (SP48329).

\section{Psidium rufum Mart. ex DC.}

Exina: sexina mais delgada que a nexina.
Medidas $(\mu \mathrm{m}): \mathrm{P}=16,0 \pm 0,24 ; \mathrm{E}=23,2 \pm 0,3$; eixo equatorial em vista polar $=22,7 \pm 0,3$; colpo compr. ca. 0,9 , larg. ca.0,5; endoabertura compr. ca. 0,2, larg. ca. 0,7 ; exina ca. 1,5 , sexina ca. 0,7 e nexina ca. 1,0 .

Material estudado: 3-X-1979, S.L. Jung et al. 299 (SP).

\section{Chave para as espécies de Psidium}

1. Grãos de pólen 3- (4)-parassincolporados, cólporos com fastígio P. guineense

1. Grãos de pólen 3- (4)-parassincolporados, cólporos sem fastígio P. catleyanum P. cinereum P. rufum

Siphoneugena O. Berg

1. Siphoneugena widgreniana O. Berg

Figuras 74-75

Forma: oblata.

Aberturas: 3-colporadas, cólporos irregularmente parassincolporados, sem fastígio, endoabertura de difícil visualização.

Exina: rugulada, sexina da mesma espessura que a nexina.

Medidas em $(\mu \mathrm{m}): \mathrm{P}=15,6 \pm 0,2 ; \mathrm{E}=21,2 \pm 0,2$; eixo equatorial em vista polar $20,0 \pm 0,2$; exina ca. 1,8 , sexina ca. 0,9 e nexina ca. 0,9 .

Observações: Para a Flora do Brasil (2020, em construção) Siphoneugena crassifolia (DC.) Proença $\&$ Sobral é o nome aceito para essa espécie atualmente.

Material estudado: 30-III-1935, F.C. Hoehne s.n. (SP32836, isótipo de Mitranthes pubescens Burret).

\section{Literatura consultada}

Barth, O.M. \& Barbosa, A.F. 1972. Catálogo sistemático dos pólens das plantas arbóreas do Brasil Meridional XV - Myrtaceae. Memórias do Instituto Oswaldo Cruz, Rio de Janeiro, Guanabara 70: 467-496.

Barth, O.M. \& Melhem, T.S. 1988. Glossário ilustrado de palinologia. Universidade Estadual de Campinas, Campinas.

Cruz-Barros, M.A.V. \& Souza, L.N. 2005. Flora polínica da Reserva do Parque Estadual das Fontes do Ipiranga (Sao Paulo, Brasil): Família: 10-Piperaceae. Hoehnea 32: 77-85.

Erdtman, G. 1952. Pollen Morphology and Plant Taxonomy - Angiosperms. Almkvist \& Wiksell, Stockholm. 
Erdtman, G. 1960. The acetolysis method. A revised description. Svensk Botanisk Tidskrift 54: 561-564.

Holmgren, P.K., Holmgren, N.H. \& Barnett, J.L.C. 1990. Index Herbariorum. Part 1. The herbaria of the world. (8th). New York Botanical Garden/International Association for Plant Taxonomy, New York.

Landrum, L.R., Kawasaki, M.L. 1997. The genera of Myrtaceae in Brazil: an illustrated synoptic treatment and identification keys. Brittonia 49: 508-536.

Lieu, J. \& Melhem, T.S. 1973. Palinologia em Myrtaceae. Hoehnea 3: $1-11$.

Lucas, E.J., Matsumoto, K., Harris, S.A., Lughadha, E.M.N., Benardini B. \& Chase M.W. 2011. Phylogenetics, morphology, and evolution of the large genus Myrcia s.l. (Myrtaceae). International Journal of Plants Sciences 172: 915-934.

Kawasaki, M.L. 2000. Flora Fanerogâmica da Reserva do Parque Estadual das Fontes do Ipiranga (São Paulo, Brasil) 88 - Myrtaceae. Hoehnea, 27: 165-186.

Melhem, T.S., Cruz-Barros, M.A.V., Corrêa, A.M.S., Makino-Watanabe, H., Silvestre-Capelato, M.S.F. \& Gonçalves-Esteves, V. 2003. Variabilidade polínica em plantas de Campos de Jordão (São Paulo, Brasil). Boletim do Instituto de Botânica 16: 1-104.

Melhem, T.S., Giulietti, A.M., Forero, E., Barroso, G.M., Silvestre, M.S.F., Jung, S.L., Makino, H., Melo, M.M.R.F., Chiea, S.C., Wanderley, M.G.L., Kirizawa, M. \& Muniz, C. 1981. Planejamento para elaboração da "Flora Fanerogâmica da Reserva do Parque Estadual das Fontes do Ipiranga (São Paulo, Brasil)". Hoehnea 9: 63-74.
Melhem, T.S., Makino, H., Silvestre, M.S.F., Cruz, M.A.V. \& Jung-Mendaçolli, S.L. 1984. Planejamento para elaboração da "Flora Polínica da Reserva do Parque Estadual das Fontes do Ipiranga (São Paulo, Brasil)". Hoehnea 11: 1-7.

Nakajima, J.N., Esteves, R.L., Gonçalves-Esteves, V., Magenta, M.A.G., Bianchini, R.S., Pruski, J.F. \& Hind, D.J.N. 2001. Flora Fanerogâmica da Reserva do Parque Estadual das Fontes do Ipiranga (São Paulo, Brasil). 159-Asteraceae. Hoehnea 28: 111-181.

Punt, W., Hoen, P.P., Blackmore, S., Nilsson, S. \& Le Thomas, A. 2007. Glossary of Pollen and Spore Terminology. Review of Palaeobotany and Palynology 143: 1-81.

Roubik, D.W. \& Moreno, P.J.E. 1991 Pollen and spores of Barro Colorado Island. Monograph in Systematic Botany 36: 1-268.

Souza, V.C \& Lorenzi, H. 2005. Botânica Sistemática Guia ilustrado para apresentação das famílias de Angiospermas da flora brasileira em AGP II: 1-640.

Thornhill, A.H., Hope, G.S., Craven, L.A. \& Crisp, M.D. 2012. Pollen morphology of the Myrtaceae. Part 4: tribes Kanieae, Myrteae and Tristanieae. Australian Journal of Botany 60: 260-289.

Tuler, A.C., Silva. T., Carrijo, T.T., Garbin, M., Mendonça, C.B.F., Peixoto, A.L., Gonçalves-Esteves, V. Taxonomic significance of pollen morphology for species delimitation in Psidium (Myrtaceae). Plant Systematics and Evolution 303: 317-327. 